The Second International Workshop on the Balance Sheet of Social Security Pensions, Hitotsubashi Collaboration Center, Tokyo, 15 December, 2005

\title{
Actuarial Neutrality across Generations Applied to Public Pensions under Population Ageing: Effects on Government Finances and National Saving
}

\author{
by \\ Heikki Oksanen \\ Directorate-General for Economic and Financial Affairs \\ Heikki.Oksanen@cec.eu.int
}

January 2006

\begin{abstract}
In welfare states, collective saving has declined to a persistently negative level, while reduced fertility and increasing longevity are leading to increasing pension liabilities. Actuarial neutrality across generations is presented as a benchmark for designing pension reforms to meet the challenges of population ageing. It is shown that this condition can be respected by a wide range of pension reforms, with very different consequences for public finance target setting. The rules for public pensions in national accounting are also discussed. Finally, the combined effects of population ageing and public pension rules on national saving are discussed.
\end{abstract}

JEL Code: H1, H5, H6.

Keywords: pensions, actuarial neutrality, public debt, national accounts.

\section{Acknowledgements}

A previous version has been published as Oksanen (2005a). I would like to thank participants of the CESifo Area Conference on Public Sector Economics, 22-24 April 2005, and of the Second International Workshop on the "Balance Sheet of Social Security Pensions", 15 December 2005, in Tokyo, especially Seiritsu Ogura, for their very useful comments and suggestions for further revisions and clarifications. I would also like to thank Andràs Simonovits for his valuable comments and advice. - Karel Havik deserves warm thanks for his valuable help in computing the reported simulations and editing the graphs, as does Cecilia Mulligan and Jeanette Bell for careful editing of the text. I am solely responsible for remaining errors and omissions.

Views expressed in the paper are exclusively those of the author and do not necessarily correspond to those of the European Commission.

(C) European Communities, 2005 and 2006 


\section{Table of contents}

1. Introduction

2. The principle of actuarial neutrality across generations extended to public pensions

3. Public finance targets under actuarial neutrality and alternative accounting rules

4. Illustrations with stylised data

5. Implications for government finances and national saving

6. Conclusions and suggestions for further work

REFERENCES 


\section{Introduction}

Government saving contributed to total national saving and growth in the European welfare states from the 1950s to the mid-1970s, but since then, has (on average) been negative (Figures 1.1 and 1.2). Fertility has declined steadily since the 1970s (Figure 1.3), while longevity has increased and is expected to continue to do so. Public pension systems, prescribing Defined Benefits (DB) and financed from current contributions on a pure PayAs-You-Go (PAYG) basis, were established in the 1950s and early 1960s.

These facts can be interpreted to mean that the generation working from the 1950 s to the mid 1970s saved collectively, thereby contributing to economic growth both for themselves and for future generations. They also established a public pension system, thereby extracting some of the increased wealth for themselves during retirement. The generation working from the mid-1970s to the present day, on the contrary, reduced collective saving to a persistently negative level. They also reduced fertility below replacement, therefore leaving a continuously declining working age population to pay for their pensions. Furthermore, their increased longevity means that, for any given retirement age, they will enjoy longer time in retirement. All this has led, not only to an increase in explicit government debt, but also to an increase in future pension liabilities to be covered from increased pension contributions or taxes to be paid by future generations. It is also obvious from the statistics that this increase in government debt (explicit and implicit) has not been compensated for by increased private saving.

The purpose of this paper is to analyse public pensions under population ageing and present a framework for analysing and designing pension reforms. As noted by Nishiyama and Smetters (2005), there is surprisingly little analytical work that looks into pensions under population ageing, while most of the work on privatisation etc. assumes a stationary population by construction. Such results might be interesting but it is astonishing that so little work has been done on the combinations of changing population structure and pension system rules, even though it is the former that has triggered the need for the latter.

To contribute to filling this gap the formal analysis in Chapter 2 is made as simple as possible to deal with the dynamic, intergenerational aspects highlighted here: people in each generation are homogenous, all work, give birth to the next generation and enjoy retirement; successive generations differ with respect to fertility and longevity; pension rights are assumed to be determined by earnings, i.e. accrued by working and paying contributions and indexed to wage rate. ${ }^{1}$ Chapter 2 first describes the dynamics over successive generations of a public pension system with fixed parameters under population ageing. Secondly, actuarial neutrality across generations is defined. It shows that this condition can be respected by a wide range of pension reforms under population ageing, with drastically different mandatory system sizes, potentially shared management between the public and private sectors, and consequently, with very different effects on government finances.

Chapter 3 discusses the rules for public pensions in national accounting, including proposals to revise them to cover pension liabilities more systematically than hitherto. Public finance target setting under alternative pension reforms and national accounting rules is also analysed.

\footnotetext{
1 The analysis could also be interpreted to cover flat rate pensions, in which case accrued pension by a generation is replaced by the future (expected) average pension of a generation as a percentage of average wage at the time of retirement. Under a flat rate system there is no link between pension and contributions or taxes for individuals. However, this is not an issue here as only intergenerational aspects are studied.
} 
Figure 1.1. General government net investment and net saving in 11 EU Member States*, 1960-2003

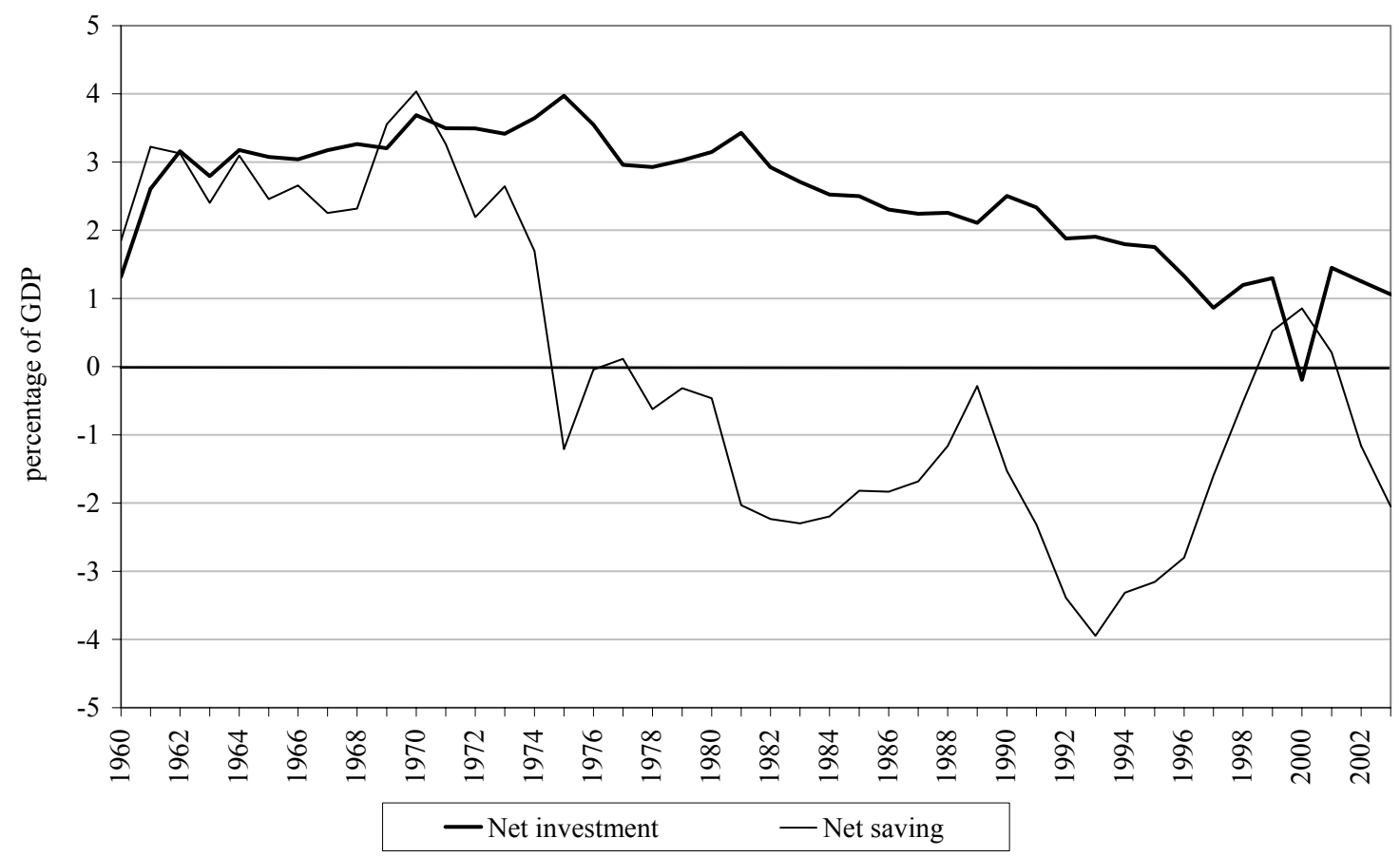

* EU-15 except EL,E,L and S due to unavailability of data Source: Commission services

Figure 1.2. Net saving in 11 EU Member States*, 1960-2003

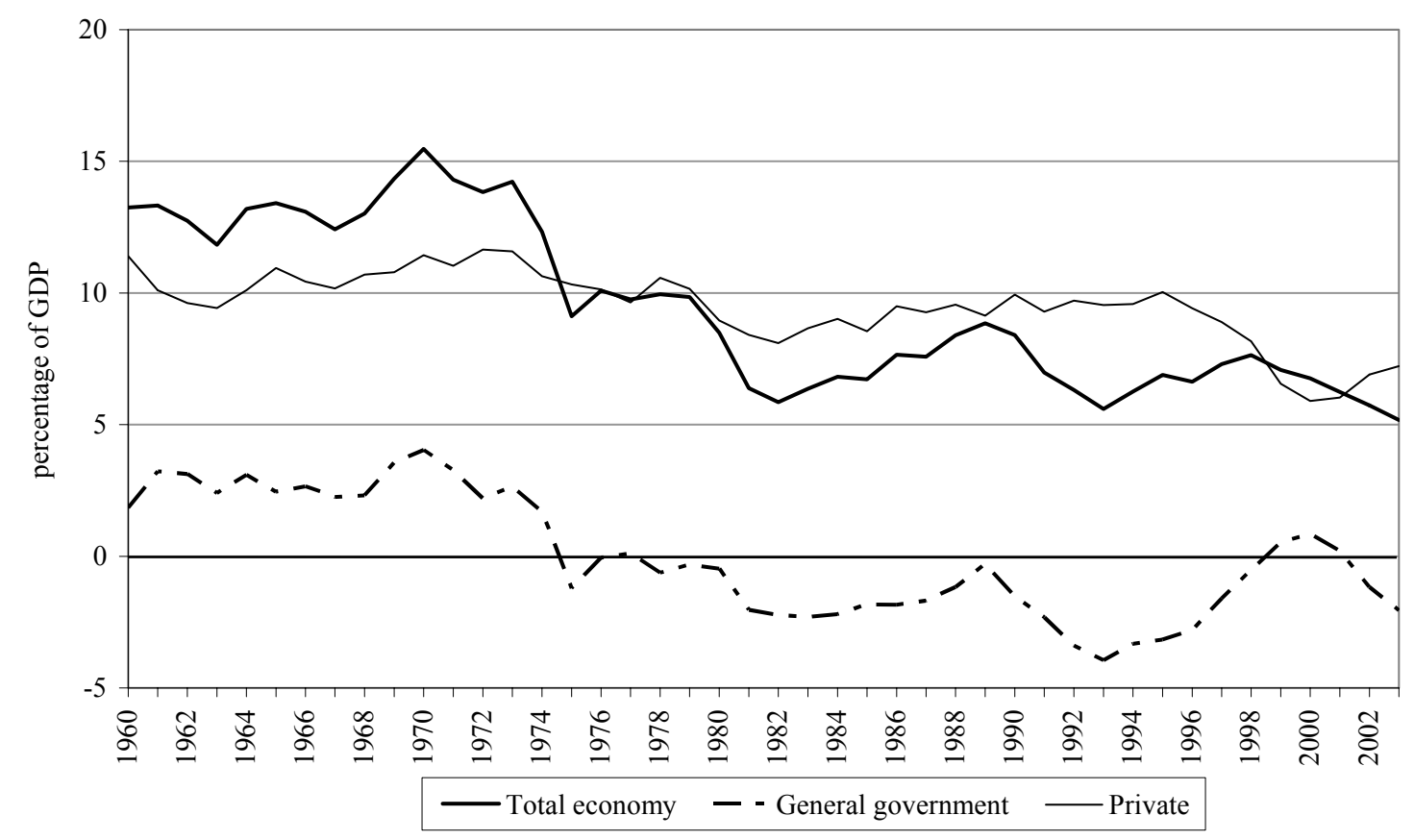

* EU-15 except EL,E,L and S due to unavailability of data 
Figure 1.3. Completed fertility* and total fertility** in EU-15

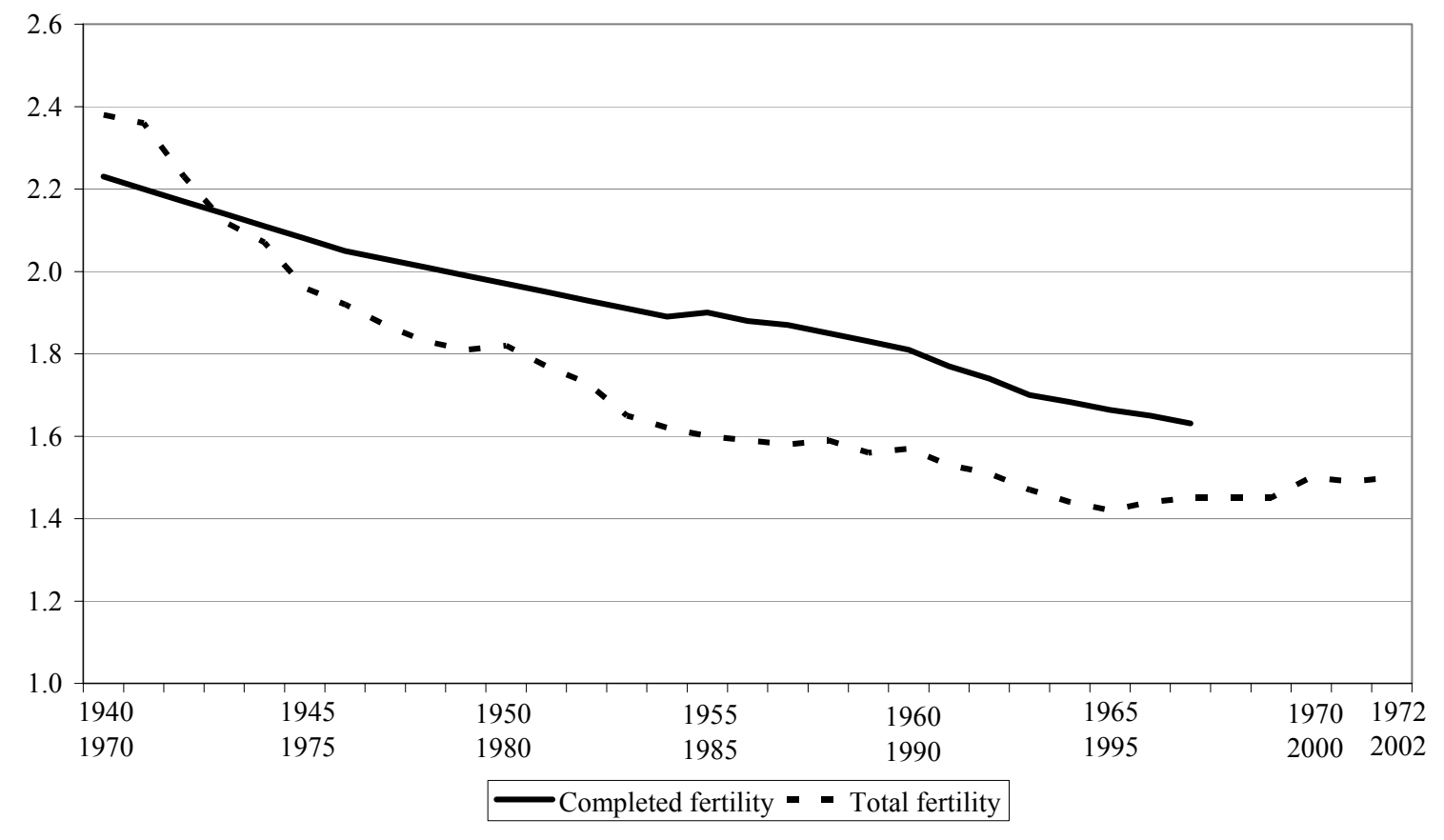

* number of children by birth year of the mother, 1940-1967,

** number of births in a given year per number of women, weighted by age-specific fertility rates of the respective calendar year, 1970-2001.

The two time scales overlap by 30 years reflecting the average childbearing age.

Chapter 4 illustrates the results with simulations using yearly stylised data.

Chapter 5 discusses the public pension rules and public finance targets under population ageing on national saving. The main messages are that population ageing (by definition a transition to the new population age structure) has drastically differing effects on saving under different pension system rules. The perspective is also extended to comments on the controversy regarding private retirement accounts for the US Social Security, while asserting that the challenges facing the relatively generous pension systems in Europe dwarf those in the US.

Chapter 6 concludes with suggestions for further work.

\section{The principle of actuarial neutrality across generations extended to public pensions}

\section{Notations and key concepts for a public pension system}

A simplest possible 3-period model is used to analyse what happens to pensions under an ageing population and to provide a framework for designing pension reforms.

The population is composed of children $(E)$, workers $(L)$ and retirees $(R)$. Each of these phases of an individual's life is, for the purpose of managing the mathematics, set to be of equal length, which is set as the unit period:

$$
E_{t}=L_{t+1}=R_{t+2} .
$$


To keep a rough correspondence with real life, the unit period is best considered to last 30 years: this is currently the average childbearing age of women, and also, by chance, roughly the difference between the average age of a pensioner (70) and that of a worker (40).

Parameter $f_{t}$ expresses the number of children per worker in period $t$ (assuming $f_{\mathrm{t}}<1$ means that $\mathrm{L}$ decreases at a rate of $\left.1-f_{t}\right)$ :

$$
E_{t}=f_{t} L_{t}
$$

The pension system delivers Defined Benefit (DB) pensions accrued at a specified rate of the wage by working and paying pension contributions. Pensions in payment are indexed to the nominal wage rate, $w_{t}$, assumed to be uniform for all.

Pension per retiree for the unit period, as a percentage of unit wage, is

$$
s_{t}=\sigma_{t} \pi_{t-1}
$$

where $\pi_{t-1}$ is the accrual rate valid for period $t$ - 1 workers determining their pension as a percentage of unit wage in the next period when retired, and $\sigma_{t}$ is a scale factor which, firstly, takes into account that in the formal analysis we artificially assume that the period at work and in retirement are of equal length; for example, if in reality the former is 40 years and the latter 17 , then $\sigma_{t}$ is $0.425(=17 / 40)$. Secondly, an increase in longevity, assuming a constant retirement age, can be introduced by assuming an increase in $\sigma_{t}$ : if people work for 40 years and longevity increases by six years, then $\sigma_{t}$ increases to $0.575(=23 / 40)$; assuming, for example, an accrual rate of $1.5 \%$ per annum, gives $\pi_{t-1}=0.6$ and $s_{t}=0.255$ in the former case and 0.345 in the latter.

To construct a case which is more general than a pure PAYG system, we allow that the system may have financial reserves, $A_{t}$ (which can be negative). The interest rate applied on assets in the previous period is assumed to be uniform. The interest factor $\rho_{t}$ is decomposed to the increase in the wage bill and a margin, $d_{t}$, as follows:

$$
\rho_{t}=\frac{w_{t}}{w_{t-1}} \frac{L_{t}}{L_{t-1}}\left(1+d_{t}\right) \text {. }
$$

Implicit pension debt $\left(I P D_{t}\right)$ is defined as the present value of next period pensions accrued in period $t$, discounted at the interest rate in period $t+1$ :

$$
I P D_{t}=\frac{s_{t+1} w_{t+1} R_{t+1}}{\rho_{t+1}} .
$$

Denoting $I P D_{t}$ as a proportion of the wage bill in the same period by $\theta_{t}$ and substituting from equations (1)-(5) we can write

$$
\theta_{t}=\frac{I P D_{t}}{w_{t} L_{t}}=\frac{s_{t}}{f_{t}\left(1+d_{t}\right)} .
$$

Degree of funding, $z_{t}$, is defined as the ratio of financial reserves $A_{t}$ to $I P D_{t}$ :

$$
z_{t}=\frac{A_{t}}{I P D_{t}}
$$


The contribution rate in period $t$ is $c_{t}$. System revenue includes pension contributions and interest on its assets, and pensions are the only expenditure item. Thus, budget balance equation for period $t$ reads as

$$
c_{t} w_{t} L_{t}+\left(\rho_{t}-1\right) A_{t-1}=s_{t} w_{t} R_{t}+A_{t}-A_{t-1} \cdot
$$

Substituting from the population dynamics equations (1) and (2), pension accrual equation (3) and equations (4)-(7) for the definitions, the contribution rate $c_{t}$ can be expressed as

$$
c_{t}=\left(1-z_{t-1}\right) \frac{s_{t}}{f_{t-1}}+z_{t} \frac{s_{t+1}}{f_{t}\left(1+d_{t+1}\right)} .
$$

This equation shows how the contribution rate is related to fertility that determines the ratio of retirees and workers in each unit period, pensions determined by the accrual rate and the ratio between time at work and in retirement $\left(s_{t}=\sigma_{t} \pi_{t-1}\right)$, the interest rate margin over the wage bill growth in period $t+1\left(d_{t+1}\right)$, and the degree of funding both in the past and in the current period $\left(z_{t-1}\right.$ and $\left.z_{t}\right)$.

The extreme case of full funding comes out by setting $z_{t}$ to 1 for the first period: the contribution rate is then equal to the present value of pension in the next period, and the system remains fully funded as long as this rule is followed.

The elementary case of pure PAYG system is derived by setting $z_{t}$ to zero for all $t$ : the contribution rate is then equal to the ratio of unit pension to unit wage divided by the relative number of retirees to workers that is determined by past fertility of the retired generation.

Pure PAYG pension systems (or more generally, less-than-fully-funded ones) emerge as some age cohorts receive pensions under a Defined Benefit rule (DB) having contributed less than the capitalised value of what they will receive, thus, in general, having paid no contributions at all or receiving on their contributions a return higher than the market rate of interest. In this case, later on, contributions need to be increased to cover the expenditure under the given benefit rule. As the system matures, workers as contributors will have to pay in contributions that exceed the present value of their own future pensions. This excess is called implicit tax. Expressed as a proportion of the wage bill, implicit tax rate, $\tau_{t}$, can be written as

$$
\tau_{t}=c_{t}-\theta_{t}=\left(1-z_{t-1}\right) \frac{s_{t}}{f_{t-1}}-\left(1-z_{t}\right) \frac{s_{t+1}}{f_{t}\left(1+d_{t+1}\right)} .
$$

Under pure DB PAYG the implicit tax is negative for the first generation by the full amount of their pensions. Later, it is positive for all future generations taken together, but it is important to note from equation (10) that it can be negative for a particular generation if its longevity is sufficiently increased and/or fertility decreased as compared to the previous generation.

Internal rate of return in the pension system in period $t, i_{t}$, is defined as the rate of return on the contributions $\left(c_{t} w_{t}\right)$ of a representative individual in terms of his/her future pension $\left(s_{t+1} w_{t+1}\right)$ :

$$
i_{t}=\frac{w_{t+1}}{w_{t}} \frac{s_{t+1}}{\left(1-z_{t-1}\right) \frac{s_{t}}{f_{t-1}}+z_{t} \frac{s_{t+1}}{f_{t}\left(1+d_{t+1}\right)}}-1 .
$$


In general, the result depends on all past and future demographic and pension system parameters and the interest rate margin in period $t+1$.

Under full funding ( $z_{t}$ is always equal to 1) equation (10) gives zero for implicit tax and equation (11) gives for the rate of return the market rate in the period of retirement.

In the particular case of pure DB PAYG the result for internal rate of return is

$$
i_{t}{ }^{\prime}=\left(\frac{w_{t+1}}{w_{t}}\right)\left(\frac{s_{t+1}}{s_{t}}\right) f_{t-1}-1 .
$$

Thus, under a pure DB PAYG system the internal rate of return depends on the change in longevity, but not on the fertility of the generation in question; as a consequence, if $f_{t}<f_{t-1}$, the next generation(s) will have to pay higher contributions for the same benefits, thus, the internal rate of return for them will fall. Note also that the unit wage increase and fertility in the previous period determine the growth of the wage bill. Thus, equation (11)' shows that the famous result by Samuelson (1958) that, under a pure PAYG system, the internal rate of return is equal to the wage bill growth, is valid not only under stable population structure (as he originally presented it) but also if longevity is constant (or more generally, if $s_{t+1}=s_{t}$ i.e. if the accrual rate is reduced to neutralise the effect of longevity increase on pension expenditure). ${ }^{2}$

\section{Actuarial neutrality extended to less-than-fully-funded public pensions}

For privately managed pension insurance, actuarial neutrality means that the present value of (expected) future pension entitlements equals the present value of contributions. Such contracts establish a fully funded pension system, either voluntary or mandatory by law. The implicit tax is zero and rate of return is equal to the market rate.

If a pure PAYG pension system is fully matured with a fixed accrual rate, and the demographic structure is stable due to constant fertility and longevity, all current and future generations pay the same contribution rate and receive the same benefits as a percentage of unit wage in each period. This arrangement can be regarded as neutral across generations in the sense that all succeeding generations equally share the burden of past not-fully-funded pensions and cover the capital value of their own pensions.

These two cases are very restrictive indeed. In what follows we extend the analysis to a less-than-fully-funded public pension system under population ageing which is, by definition, a change in the age structure due to a decline in fertility and/or to an increase in longevity changing the ratio of time in retirement/at work (for a given retirement age).

For defining actuarial neutrality across generations it is instructive to note that the burden of explicit public debt and implicit pension debt are parallel though not identical. As Diamond and Orszag (2004, pp. 37-38) put it, explicit public debt reflects the accumulated difference between the spending and revenue from the beginning of the nation to the present, and in parallel, under the public pension system, implicit pension debt reflects the accumulated difference between pension benefits for and contributions paid by previous and current generations. Both require that taxes (including pension contributions) are higher

\footnotetext{
2 The concepts of IPD, implicit tax and internal rate of return for pure PAYG systems are worked out, for example, by Uebelmesser (2004). Above, their definitions and derivations are more general, as any degree of funding is allowed for.
} 
than in the case where expenditure was covered by revenue and pension benefits were prefinanced when rights were accrued (i.e. fully funded).

With regard to serving public debt in a growing economy, discarding for simplicity borrowing for the accumulation of capital, neutrality across generations can be defined as maintaining the given debt level as compared to the scale of the economy. In the present context, looking only partially into the public pension system, we do not formally cover explicit public debt although inserting it as a negative component to $A_{t}$ above would make this straightforward.

With the above principles in mind, the concept of actuarial neutrality can be extended to public less-than-fully-funded pensions by defining as actuarially neutral the pension contribution rate, $c^{a}{ }_{t}$, so that the contribution revenue covers (1) the interest on the past net debt, including its implicit and explicit components minus its growth in nominal terms allowed by the growth factor, and (2) the present value of the future pensions of current workers.

One more additional simplifying assumption will prove to be useful: the rate of interest over the rate of growth of the wage bill, $d_{t}$, is constant, i.e.

$$
d_{t}=\bar{d} \text { for all } \mathrm{t} .
$$

With this additional assumption the results will turn out to be very clear and simple. The more general case for changing $d_{t}$ will be discussed separately.

Furthermore, the ratio of assets to the wage bill is denoted by $q_{t}$ :

$$
q_{t}=\frac{A_{t}}{w_{t} L_{t}}
$$

Substituting from (4)-(7) and (12)-(13) we can write

$$
c^{a}{ }_{t}=\bar{d} \frac{I P D_{t-1}-A_{t-1}}{w_{t-1} L_{t-1}}+\frac{I P D_{t}}{w_{t} L_{t}}=\bar{d}\left(\theta_{t-1}-q_{t-1}\right)+\theta_{t}=\left(1-z_{t-1}\right) \frac{s_{t}}{f_{t-1}} \frac{\bar{d}}{(1+\bar{d})}+\frac{s_{t+1}}{f_{t}(1+\bar{d})} .
$$

The first two expressions give $c^{a}{ }_{t}$ as the sum of the implicit tax in this particular case and $I P D_{t}$ as a percentage of the wage bill, and the last formula gives it as a function of the demographic and pension system parameters and the interest rate margin in periods $t$ and $t+1$.

Inserting (14) to the general equation (8) for the contribution rate gives a clear cut implication for actuarial neutrality:

$$
\frac{I P D_{t}-A_{t}}{w_{t} L_{t}}=\frac{I P D_{t-1}-A_{t-1}}{w_{t-1} L_{t-1}} \text { or } \theta_{t}-q_{t}=\theta_{t-1}-q_{t-1} .
$$

Thus, under actuarial neutrality the net debt, i.e. IPD minus financial assets of the system, related to the scale of the economy, remains constant, regardless of any changes in demographic factors and/or pension system parameters. Similarly, the implicit tax to be paid by all future generations will remain the same. 
The rule of actuarial neutrality can be extended to cover a changing interest rate margin $d_{t}$ relatively easily, without entering into any formal treatment. The key is at each point in time to apply the same (currently prevailing) assumption on its value both for serving the past debt and for calculating the present value of future pensions.

One implication of this rule is that the picture of a pure PAYG under a stable population is consistent: even if $d_{t}$ changes, the contribution rate remains constant and the revenue covers expenditure; only the composition of the contribution rate alters as the changes in implicit tax and in the present value of future pensions match each other.

It is also instructive to see what happens under Defined Benefits and full funding: if the return on assets is higher (lower) than expected, the pension provider incurs a gain (loss). Sticking to the rule of actuarial neutrality, given the expectations in each period, this gain (loss) is shared equally across all future generations. In the case of a private provider, sharing a loss is generally not possible as the provider may go bankrupt. In such a case, some adjustment would need to be made in which case the system de facto would move towards a Defined Contribution (DC) system.

Under the general case of a partially funded public DB pension system, a change in $d_{t}$ from $t-1$ to $t$ leads to an unexpected return on assets. If the rule of actuarial neutrality is followed in setting the contribution rate in period $t$, the gain (loss) is shared equally between all current and future generations. The IPD $\mathrm{I}_{\mathrm{t}-1}$ is revalued at the interest rate in period $t$, and, as a result, the net debt ratio changes and an imputed capital gain (loss) occurs. This new debt ratio and the new $d_{t}$ are the basis for setting the contributions rate.

Similar principles apply to other unexpected changes. Note, however, future fertility does not enter into the equations and the accrual rate is set as a policy parameter. Thus, under the three-period model here, longevity incorporated in $\sigma_{t}$ above is, in addition to $d_{t}$, the only genuinely uncertain factor that needs to be projected for period $t+1$. If the realisation differed from the assumption, a gain (loss) occurs, and the outcome differs from actuarial neutrality ex post. Again, if actuarial neutrality were to be followed from this point onwards, the recalculated net debt should be the basis for current and future decisions.

\section{Public finance targets under actuarial neutrality and alternative accounting rules}

\section{Fiscal targets under actuarial neutrality and current national accounting}

A pure PAYG system is, by definition, always in financial balance in terms of conventional accounting, though this platitude is not very helpful for understanding the economic and political issues at stake when population ageing puts pressure on the pension system and necessitates changes to its rules.

As pure PAYG is generally not actuarially neutral under population ageing, it is useful to work out with the help of equation (14) above, the implications of this latter principle for the explicit government net debt and the budget balance. Under conventional accounting for explicit assets (and debt), maintaining the assumption of a constant $\bar{d}$, the change in the asset ratio under actuarial neutrality reads as:

$$
q^{a}{ }_{t}-q_{t-1}=\theta_{t}-\theta_{t-1}
$$


Denoting the rate of growth of the wage bill by $g_{t}$, i.e.

$$
g_{t}=\frac{w_{t+1} L_{t+1}}{w_{t} L_{t}}-1
$$

we can express the conventionally defined budget balance under actuarial neutrality as a percentage of the wage bill, $b^{a}{ }_{t}$, as

$$
b^{a}{ }_{t}=\theta_{t}-\theta_{t-1}+\frac{g_{t}}{1+g_{t}} q_{t-1} .
$$

The last term gives the budget balance in a steady state where the demographic factors, pension system parameters and the interest margin $d$ are constant and the first two terms therefore cancel each other out.

Under population ageing and changes in pension system parameters, actuarial neutrality implies, as expressed in equation (15), that the increase in financial assets/wage bill ratio $q_{t}$ is equal to the increase in IPD/wage bill ratio $\theta_{t}$. Note that this increase does not depend on the past value of assets/wage bill ratio, and that this is valid for any degree of funding, including a fully funded system. The intuitive explanation is that people need to contribute more into the fund as longer life expectancy increases the capital value of pension required for any given replacement rate and as the rate of return falls (as the decrease in fertility causes a decline in the number of workers). In this way, a fully funded system is equally exposed to population ageing as any other system, and the increase in $q_{t}$ is the same as in any other case complying with actuarial neutrality.

Thus, according to (15), under ageing population and actuarial neutrality, the ratio of financial assets to wage bill generally changes; for example, the system moves from pure PAYG to partial funding unless generosity of pensions is sufficiently reduced. The condition for the latter, derived from equation (3) and the budget balance for a pure PAYG with a fixed contribution rate, is:

$$
\frac{\pi_{t}}{\pi_{t-1}}=\frac{\sigma_{t}}{\sigma_{t+1}} \frac{f_{t}}{f_{t-1}} .
$$

In this case, the size of the pension system measured by the contribution rate remains unchanged, while generosity measured by the replacement rate adjusts downwards. If future benefits are reduced further than this, i.e. the IPD/wage bill ratio is reduced, an increase in government debt ratio is implied by the neutrality rule.

The result in equation (15) helps to clarify the issue of 'double burden', often referred to with regard to moving to (partial) funding of public pensions: actual neutrality, without adequately decreasing the replacement rate and/or increasing the retirement age will require a move to partial funding. Thus, there is not necessarily any excessive 'double burden' for the current generation of workers even if the system moves to partial funding, while actuarial neutrality can be understood to determine a threshold beyond which pension contributions (or taxes) become excessive. ${ }^{3}$

Note that these equations do not in any way determine the future size of the public pension system, i.e. the level of benefits in period $t+1$ and onwards. They only give an actuarially neutral set of pension system parameters (accrual rate and contribution rate) under each set

\footnotetext{
${ }^{3}$ The results above reiterate those in Oksanen (2004). Sinn (2000) gave the inspiration to look into the arguments for moving to partial funding under population ageing.
} 
of demographic parameters. Moreover, actuarial neutrality is not presented here as an ultimate norm for public finance targets, but as a useful benchmark only. It does not bring into question the legacy of IPD from the past but rather recognises it as a burden to be shared equally between the current and all future generations. This is not to deny that reasons might well exist to depart from actuarial neutrality and share this burden differently, but the present framework merely provides a tool for arguing about such options. Note however, that the approach here directly challenges the view that continuation of a pure PAYG public pensions should be taken for granted. Equation (18) above shows that, under pure PAYG, actuarial neutrality is respected only if the benefits are sufficiently reduced. As this might, under population ageing, be in conflict with adequacy, especially if a significant increase in retirement age is not envisaged, a departure from pure PAYG might be justified.

The rule of actuarial neutrality can also be compared with Musgrave's (1986) 'fixed relative position' rule for determining a fair pension formula, referred to in recent discussion, e.g. by Esping-Andersen et al. (2002). It means that pensions under a pure PAYG system are indexed to the wage rate after pension contributions. It is true that this Musgrave rule, like the rule of actuarial neutrality above, distributes the benefits of an exogenous change in productivity of labour equally between current workers and retirees through the wage index. However, it deviates from actuarial neutrality and leads under population ageing to an increasing burden for future generations. This could be most simply proven with a case where fertility decreases and longevity increases permanently: the first generation with the new demographic characteristics will have paid less for the same benefits than the similar generations which follow. ${ }^{4,5}$

Finally, actuarial neutrality as developed here gives a direct input for setting public finance targets also for a more general case with legacy of explicit public debt. The increase in pension fund assets from equation (15) should enter as a target for the reduction of the net public debt ratio, and the budget balance from equation (17) should be added to the (negative) budget balance target that would keep the net debt ratio constant. This type of framework for setting public finance targets, which consistently integrates the public pension system to the rest of government finances, is indispensable for any pension financing rules - prescribing actuarial neutrality or other principles - to have their intended effects (for further comments, see Section 5 below).

\section{Actuarial accounting for public pensions}

The current System of National Accounts 1993 (SNA-93) and, in parallel, the European System of Accounts (ESA-95) neither recognise the implicit pension debt of public DB pension systems in the balance sheets nor the effects of its changes for budget balance. Thus, government commitments to future pensions (or changes therein) do not affect a government's financial position at the time of making them.

\footnotetext{
${ }^{4}$ Myles (2003) asserts that people who were advised in the 1960s not to have too many children in order not to overburden the earth should not be punished for their reduced fertility. This is beside the point here as the consequences of declined fertility on pension systems should be treated regardless of the underlying reasons. The right question is why the first generation with declined fertility should be treated more favourably than any hypothetical identical generation later. See also Schokkaert and Van Parijs (2003).

${ }^{5}$ Note that, in the simple framework above, parameter $\sigma_{t}$ for the ratio between time at work and in retirement captures, in addition to increasing life expectancy, an increase in retirement age. This is applicable for describing the new steady state after such a change. However, the transitional effect of the rate of change in work force due to such a change is not contained in this simple framework. Thus, the equations above are fully applicable only under the assumption of a fixed retirement age. This issue will be further explored with the help of yearly data simulations below.
} 
For companies, the national accounting rules currently recognise the pension obligations as employer liabilities only if those obligations are funded, i.e. if they are (fully or partially) matched by segregated assets. As the nature of this obligation does not qualitatively depend on the mode of meeting it, and as such liabilities considerably affect the value of a firm, the main existing company accounting standards require their recording, whether funded or not. For example, since 2005, all listed companies in the European Union are required to record all their pension liabilities according to the International Accounting Standards provision IAS19.

Since 2001 the international statistical community has prepared a revision of national accounting rules for pensions, aimed at (1) a rapprochement of the treatment of employer pension schemes in company accounts and in national accounts and (2) consistency of national accounting rules for all pensions in all sectors. ${ }^{6}$ Therefore, it has been proposed that all employer pension liabilities be recorded as debt, including those of government, regardless of whether segregated assets back them or not (de Rougemont, 2003, OECD Statistics Directorate, 2004, Statistics Department, IMF, 2004; also Oksanen, 2005b). This change alone would have a significant effect on government accounts. If and when national accounting rules would be revised so that all public pension liabilities (i.e. social security and social assistance) would be treated as public debt, has remained controversial, the main reason being the difficulty in estimating government IPD as it is often open to interpretation and is sensitive to small changes in assumptions (future interest rate, for example). Consequently, it has been proposed that, at least for the time being, estimates for government IPD will be presented separately, outside the main body of government statistics, thereby providing statistics to be used for specific purposes without effecting daily monitoring of public finances (Lequiller, 2005). Whether public pension liabilities are eventually recorded in core accounts or not, certain conceptual issues must nonetheless be resolved to create a consistent set of accounting rules.

The concepts defined above provide the required conceptual framework to extend actuarial accounting principles to public pensions, albeit recognising the main differences between company pension schemes and public social security pensions. In the former, pension liability is a negative entry in the net worth of a corporation, whether segregated assets match this liability or not, and pension contributions, whether explicitly paid or imputed, are recorded as a financial transaction.

\footnotetext{
${ }^{6}$ Beyond the general aim of harmonising corporations and government sector rules to a maximum, an important practical reason also exists: pension liabilities are sometimes shifted from a corporation to the government against a compensatory payment, often a lump-sum; this has recently happened in cases of public corporations, especially in the context of their reorganisation or privatisation. In such cases, the way these transactions are recorded has a crucial impact on government deficit, which is why Eurostat - the statistical arm of the European Commission - has in the recent past dealt with such cases in the context of validating government deficit figures. It came to the conclusion that the most consistent way under the current rules is to record the payment received by the government as government revenue, thus with a positive impact on government budget balance. The problem is that the pension liability taken over by the government as the counterpart of the lump sum received is not recorded in the accounts (Eurostat news release of 21 October, 2003, on cases with an unfunded company scheme, and that of 25 February, 2004, on the corresponding cases where it is funded). - Pension liabilities can also be transferred in the other direction, causing similar accountancy problems of consistency. These cases appear under partial privatisation of the public pension system, as a portion of pension contributions is diverted to a private sector managed pension fund, thus causing an immediate decrease in government revenue, while public pension expenditure decreases gradually. Eurostat has clarified the treatment of these cases and confirmed that such an operation has a negative impact on government budget balance (Eurostat news release of 2 March, 2004).
} 
A typical unfunded public pension scheme differs from a corporate one in that it is mandatory by law and its obligations are mostly covered by compulsory pension contributions or other taxes imposable by government. Alongside IPD, implicit tax inherent in public pure or less-than-fully-funded pension schemes is a key concept to arrive at consistent actuarial accounting for both corporations and governments.

First, including IPD in the balance sheet as a component of public debt is a straightforward consequence of actuarial (or accrual) accounting. Possible financial assets, other than government bonds that are netted out under consolidated accounts, held by the public pension scheme are naturally a negative public debt entry. Thus, in the present framework, net total public debt is $I P D_{t}-A_{t}$ (again, it would be easy to include here explicit public debt and the consequent primary surplus component to serve it).

The corresponding budget balance under actuarial accounting is negative of the change in this debt from the previous period. Still maintaining the assumption on a constant $\bar{d}$, this can be expressed as a percentage of the wage bill, $b(a c t)$, as follows:

$$
b(a c t)^{a}{ }_{t}=\theta_{t}-\theta_{t-1}+\frac{g_{t}}{1+g_{t}} \theta_{t-1}
$$

where $g_{t}$ is the wage bill growth rate.

Under a steady state the first two terms cancel out, thus the budget balance is the product of the growth rate and the debt ratio. More importantly, this same result is valid for actuarial neutrality, as the first two terms are then equal, with an infinite number of possible combinations of pension system and demographic parameters. Therefore, fiscal targets under actuarial neutrality and accrual accounting become simple: constant total debt ratio and budget balance that is consistent with it (changing only with the change in the rate of growth of the economy, $\left.g_{t}\right)$.

To sum up, the budget balance under the actuarial accounting system can be decomposed, with the help of the concepts and equations above as follows: revenue includes the implicit tax and the return on assets, and expenditure is the imputed interest payment on the contributions less implicit tax in the previous period. Contributions less implicit tax are treated as a financial transaction, giving rise to a government liability to the household sector, and the payment of a pension is a depletion of this liability.

Extending actuarial accounting to public pensions would allow for consistent treatment of pension liabilities of government and corporations and of the corresponding pension assets of households. It also draws attention to pension policies and warns of an increase in future expenditure already when the rights are accrued.

The effect of the proposed explicit recording of public pension liabilities is naturally that the figures for total public debt increase to a new order of magnitude and that any policy rules linked to public debt and deficit need to be thoroughly reviewed. In European welfare states IPD of the pure PAYG systems might be $300 \%$ of GDP. If growth of nominal GDP is a moderate $3.3 \%$ per annum (see the illustrations below), and if a pension reform respecting actuarial neutrality prevents the net debt of the system from increasing as a percentage of GDP, deficit under actuarial accounting is nearly $10 \%$ of GDP! This follows from the sheer definition of budget balance: it is the change in net assets in nominal terms. As actuarial accounting displays a large stock of debt, its change is significant also in the case that the stock as a percentage of GDP is constant (which could be a benchmark for an economically balanced and acceptable scenario). 


\section{Illustrations with stylised data}

In line with the 3-period model above the results here are illustrated with stylised yearly data. The gradual maturation of a pure PAYG system providing Defined Benefits is first described by assuming a stationary population (i.e. fertility is 2.1 per woman and longevity is constant). All people live 20 years as children, work for 40 years until the age of 60 , and enjoy retirement for 17 years. Each year, workers earn pension rights equal to 1.5 percent of their salary, so that working for 40 years gives a 60 percent replacement rate. It is also assumed, as is normally the case under public pension systems, that each year all workers pay the same contribution rate irrespective of their age.

The real wage growth rate is assumed to be 1.75 percent per annum. Inflation is assumed at 1.5 percent p.a. Interest rate is assumed to be uniform at 1.5 p.p. above the rate of change of the wage bill. ${ }^{7}$

To illustrate the gradual maturing of the pension system that takes 57 years, i.e. the full working life and retirement of a 20 -year old member, it is assumed to be established in 1920. The contribution rate in 1977 is $25.2 \%$ and the IPD $568 \%$ of the wage bill.

Then, we first assume that fertility starts to decline in 1971 and gradually falls to 1.7 in 2000. This is roughly the observed decline in Western Europe ${ }^{8}$. From 2000 onwards it is assumed to be constant (this is roughly what is assumed for population projections). Secondly, longevity is assumed to increase by one year in every decade from 1990 to 2050.

We want to express some of the key variables as percentages of GDP. For this, wage bill after pension contributions is set at 40\% of GDP in 2000; for the future, it is set to decrease to allow for the increase in pension contributions. These simple assumptions imply a pension expenditure of $10.9 \%$ of GDP in 2000 and $15.3 \%$ in 2050 . The former figure corresponds to the data in the Economic Policy Committee (EPC) report of 2001. The latter figure gives the full effect of population ageing under the parameters assumed here. It is higher than projected in the EPC report, which assumes various changes in pension systems and employment patterns.

Figure 4.1 gives the IPD as a percentage of the wage bill for the stationary population, declined fertility and the combination of declined fertility and increasing longevity. The steady state under both of these population ageing factors is reached in 2050. Pension expenditure is then $43.1 \%$ and IPD $1045 \%$ of wage bill.

Next, we display the effect of implementing the principle of actuarial neutrality from 2005 onwards, assuming first that the initial pension benefits are maintained (including retirement age at 60), see Figure 4.2. The contribution rate is increased to cover the implicit tax set to serve the implicit debt accumulated by 2004 and the newly accrued rights (NAR/wb) from 2005 onwards. In 2005 the contribution rate jumps well above pension expenditure as a percentage of the wage bill and then gradually increases to $39 \%$. Under pure PAYG it would increase to $43.1 \%$.

\footnotetext{
7 This assumption means that real interest is first 3.3\% and then declines to $2.6 \%$ along with the falling rate of growth. As for sensitivity of the results, for example, IPD is $1045 \%$ of wage bill under population ageing in the first scenario below, while it is $891 \%$ if interest rate differential were 1 percentage point higher.

8 This refers to 'completed fertility' indicating the number of children of women who have passed fertile age. It is distinct from 'total fertility', which gives the ratio of births to women of fertile age. As the average age at which women give birth has recently increased, 'total fertility' has been lower than 'completed fertility'.
} 
Figure 4.1. Implicit pension debt under alternative population scenarios (per cent of wage bill)

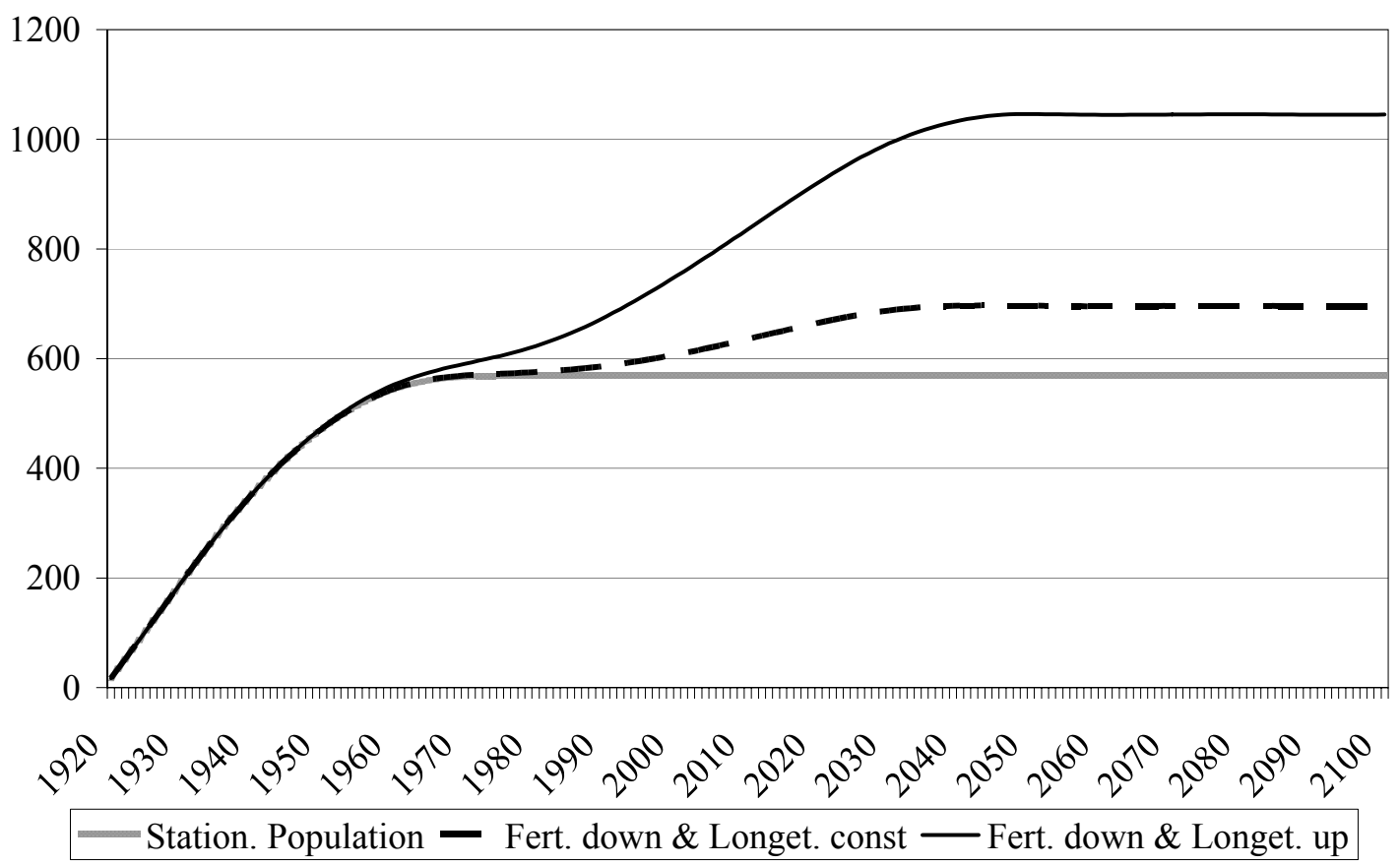

For assumptions, see the main text.

Figure 4.2. Actuarial neutrality from 2005 onwards under initial benefits

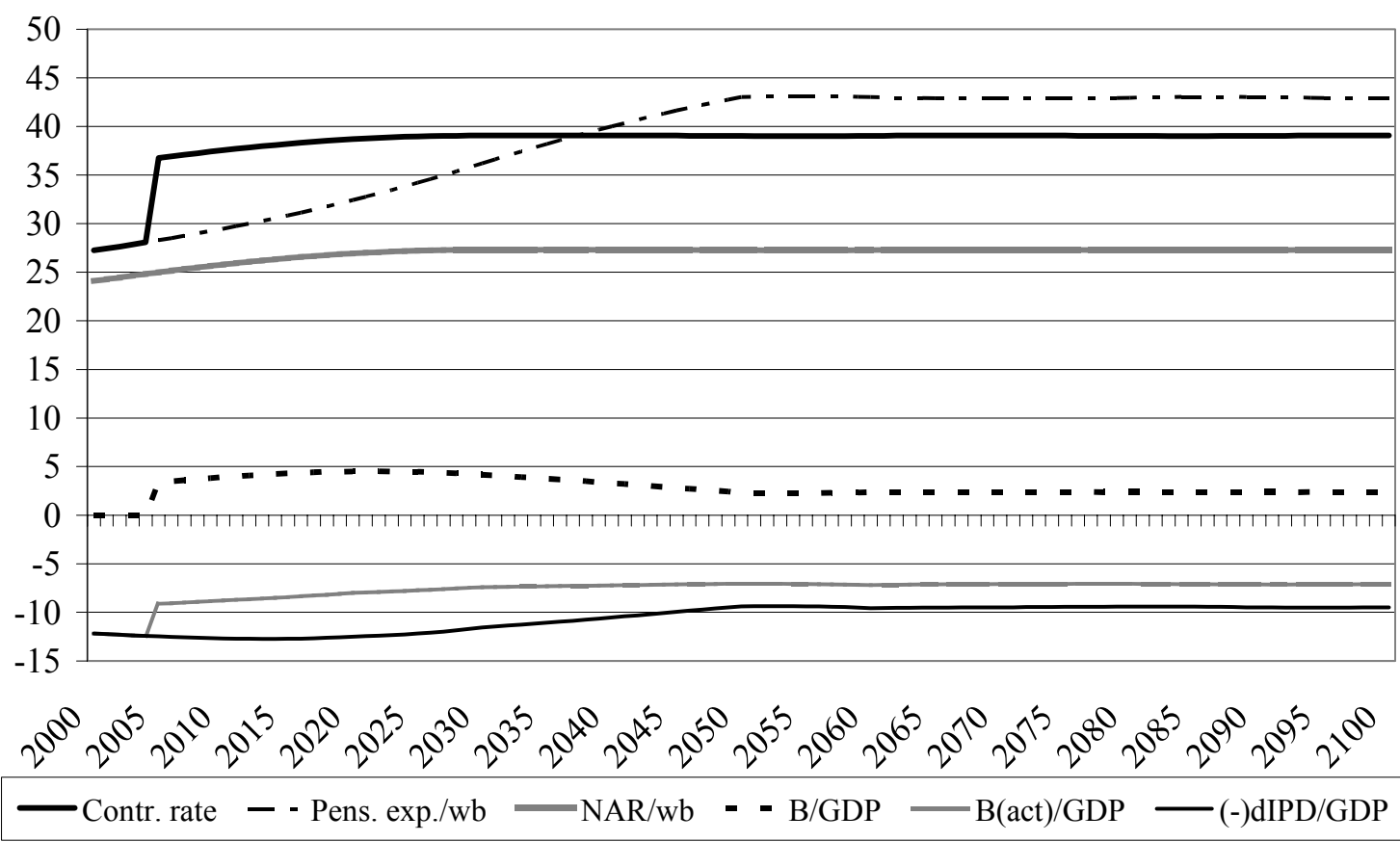

Contr. rate $=$ contribution rate as a percentage of wage.

$\mathrm{NAR} / \mathrm{wb}=$ present value of newly accrued rights as a percentage of wage bill.

Pens. exp./wb $=$ pension expenditure as a percentage of wage bill.

$(-) \mathrm{dIPD} / \mathrm{GDP}=$ negative of the change in Implicit Pension Debt as a percentage of GDP.

$\mathrm{B}(\mathrm{act}) / \mathrm{GDP}=$ budget balance under actuarial accounting rules as a percentage of GDP.

$\mathrm{B} / \mathrm{GDP}=$ budget balance under current national accounting rules as a percentage of GDP.

For assumptions, see the main text. 
Figure 4.3. Actuarial neutrality from 2005 onwards, accrual rate reduced to $1.125 \%$

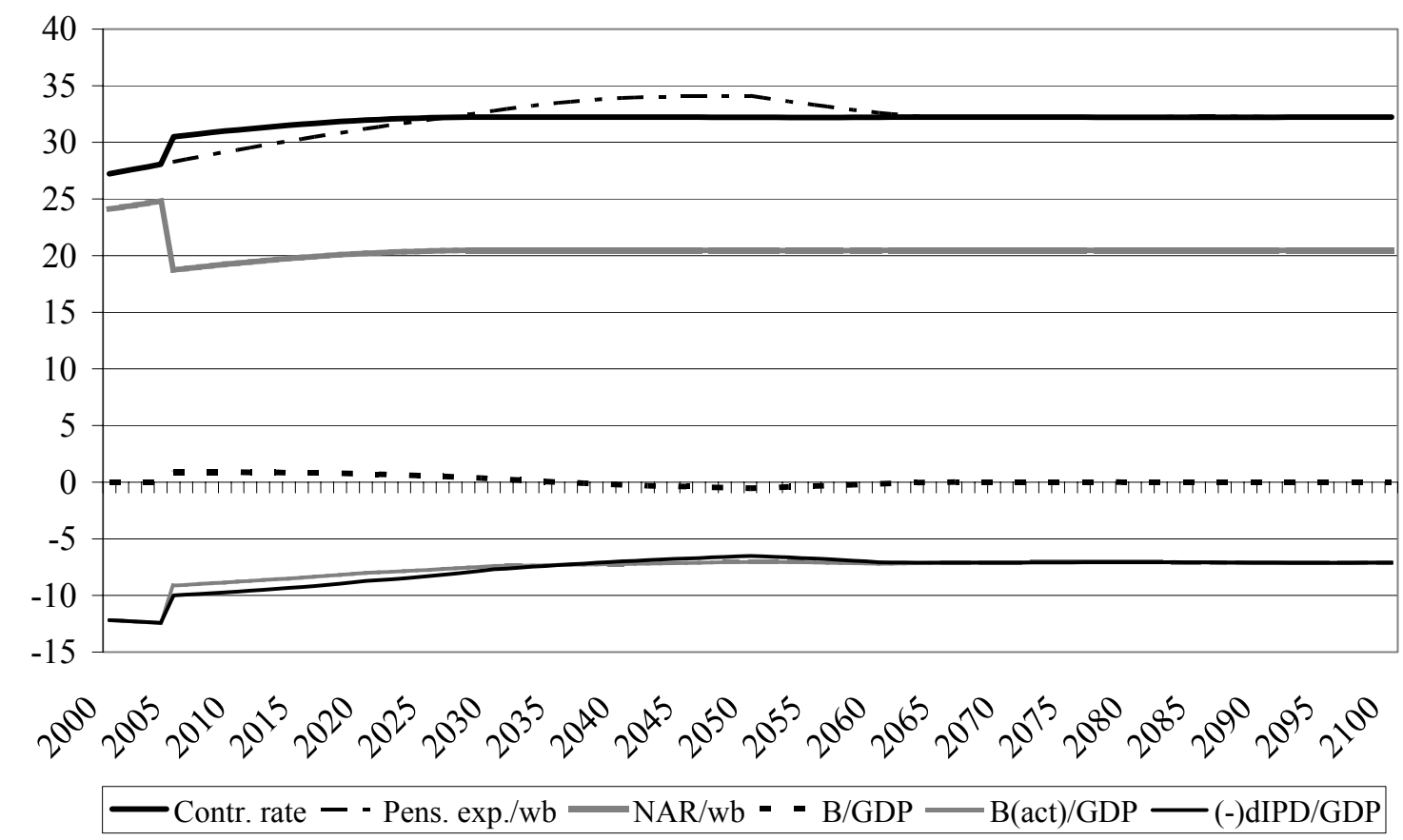

Contr. rate $=$ contribution rate as a percentage of wage.

$\mathrm{NAR} / \mathrm{wb}=$ present value of newly accrued rights as a percentage of wage bill.

Pens. exp./wb = pension expenditure as a percentage of wage bill.

$(-) \mathrm{dIPD} / \mathrm{GDP}=$ negative of the change in Implicit Pension Debt as a percentage of GDP.

$\mathrm{B}(\mathrm{act}) / \mathrm{GDP}=$ budget balance under actuarial accounting rules as a percentage of GDP.

$\mathrm{B} / \mathrm{GDP}=$ budget balance under current national accounting rules as a percentage of GDP.

For assumptions, see the main text.

Note that in each year all workers pay the same contribution rate. This means that during the adjustment period actuarial neutrality cannot be perfectly attained: for example, if fertility declines and the contribution rate is therefore increased; this also has repercussions on older workers with the initial fertility rate as well as allowing younger workers to pay less than they should. This is a consequence of the usual restriction that there is no agediscrimination with regard to the contribution rate. Therefore, for the transition period, the calculations show results that approximate to actuarial neutrality.

Figure 4.2 also displays the annual IPD change and shows that it is well above $12 \%$ of GDP through the late 2020s, which indicates that under pure PAYG IPD/GDP is still increasing considerably. By definition, actuarial neutrality means that assets are accumulated to keep the total debt/GDP ratio at its 2004 level of $311 \%$ GDP. Conventional budget balance peaks at $4.5 \%$ of GDP around 2020 and then adjusts to its steady state level of $2.3 \%$. Assets/GDP ratio increases to $95 \%$ of GDP, which, by definition of actuarial neutrality, is the increase in the IPD/GDP ratio from 2004 to its steady state value. Budget deficit under actuarial accounting immediately reduces to its actuarially neutral level; note that the smooth decrease taking place after 2005 only stems from the decrease in the rate of growth of the economy as the total net debt/GDP ratio is constant.

Significant accumulation of assets in the pension fund as such may not make this scenario grossly unrealistic as figures above $100 \%$ of GDP are found for quasi-mandatory systems in Denmark and the Netherlands, and privately managed pension provisions in the UK. What makes the scenario unrealistic is the huge increase in the contribution rate. However, 
this illustrates the cost of the assumed benefit rules, comprising of the replacement rate and retirement age. Distribution of this cost across generations should be seriously addressed and actuarial neutrality gives a useful benchmark.

Actuarial neutrality across generations does not, however, prescribe the future size of the public pension system determined by pension accrual from now onwards. A simple illustration is given in Figure 4.3 where the accrual rate is assumed to have decreased from $1.5 \%$ per annum to $1.125 \%$, leading to a replacement rate decline to $45 \%$ after the full career of 40 years. Actuarial neutrality implies that the contribution rate jumps from $28.1 \%$ in 2004 to $30.5 \%$ in 2005 and then smoothly increases to $32.2 \%$, determined by the demographic changes taking place. Over the transition, limited assets are first accumulated and then depleted. In the steady state total net debt is equal to IPD in 2004. Budget deficit under actuarial accounting is the same as in Figure 4.2 or in any other case respecting actuarial neutrality.

Figures $4.4 \mathrm{a}-\mathrm{b}$ illustrate an extreme case where actuarial neutrality is respected and the pension system is gradually scrapped by reducing the accrual rate to zero in 2005 . From 2005 onwards the workers pay a tax for serving the implicit debt, but this is the only revenue of the system. Pension expenditure gradually reduces and the system explicitly goes into debt. After the transition, lasting 63 years, the 2004 IPD of 311\% of GDP has become explicit debt.

Budget balance under current national accounting first reduces as pension contributions are suddenly reduced from $28.1 \%$ to $11.8 \%$, and then the deficit increases further as the effects of the ongoing population ageing continue to increase pension expenditure until the opposite effect of the cessation of pension rights accumulation sends pension expenditure to a decline. All these dynamic factors mean that the conventionally defined budget deficit reduces to its steady state value only after 63 years after the change. Again, budget deficit under actuarial accounting is the same as in the case above.

The same pattern of budget deficit under the two parallel accounting rules would recur under any newly determined accrual rates in between the cases in Figures 4.2 and 4.4. This would happen under a partial privatisation of the pension system by diverting part of the pension contributions to a newly established mandatory privately managed fully funded pillar and reducing the accrual rate in the public pillar consistently with actuarial neutrality. Note that a consistent reform requires that the implicit tax due to the past accumulation of IPD is maintained as public sector revenue, and the rest of initial contributions is shared between the public and private pillars consistently with the new accrual rate in the public pillar. Under an assumption of a uniform interest rate the total replacement rate is not affected by the establishment of a two-pillar system.

Note also that the case in Figure 4.2 above where initial accrual rates are maintained and asset accumulation therefore takes place could be privatised up to a certain proportion without incurring debt: under an actuarially neutral reform, the assets would then accumulate in the privately managed system. This observation links the assessment of the merits of privatisation to the views about time consistency of economic policy. The question is, do people trust the public sector as manager of their pension assets? Various institutional arrangements - including involvement of labour market organisations - exist to draw a line between assets in the mandatory or quasi-mandatory pension system and government's coffers. 
Figure 4.4. Actuarial neutrality from 2005 onwards, accrual rate zero

a. IPD, total debt and explicit debt as per cent of GDP

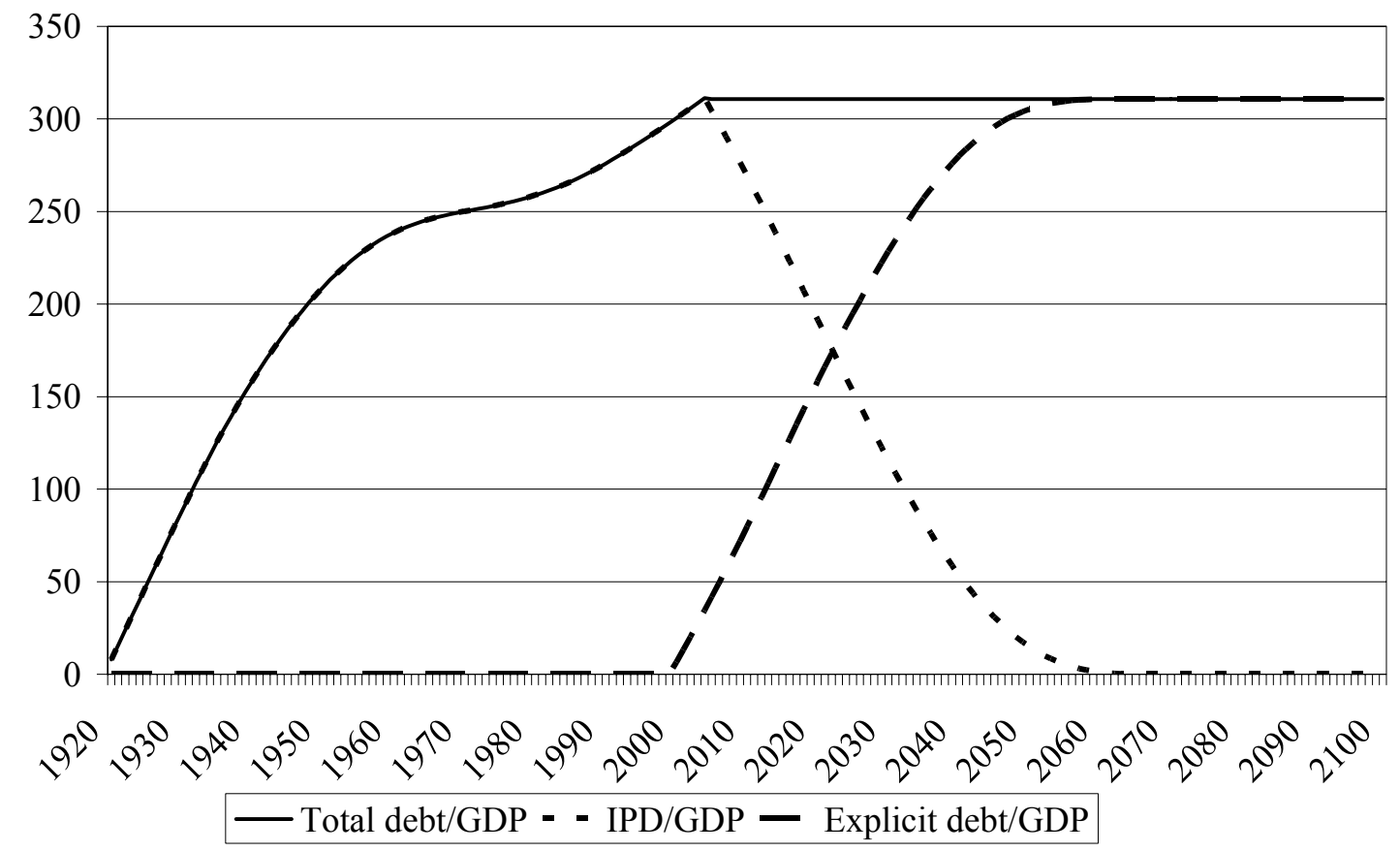

b. Other variables

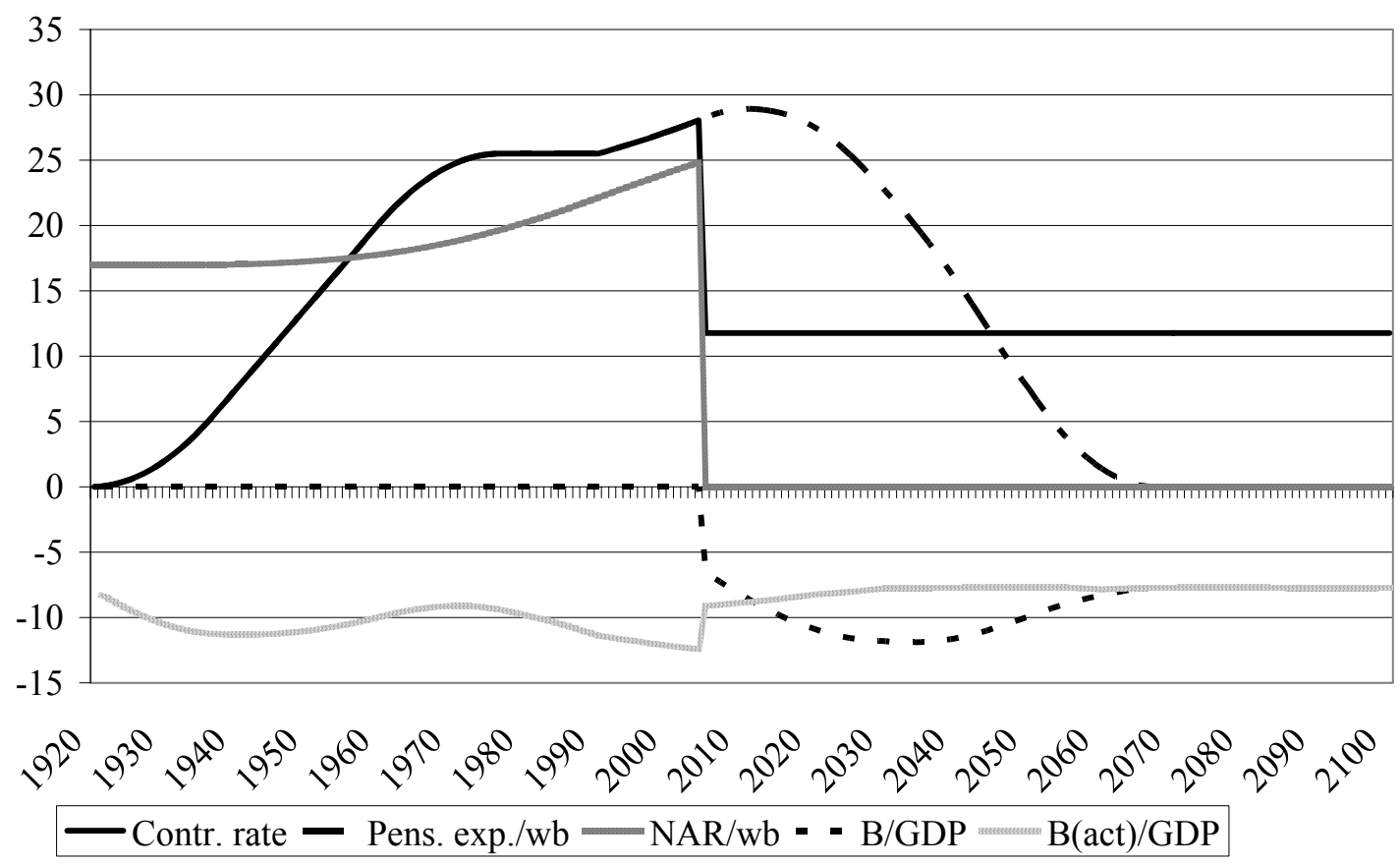

Contr. rate $=$ contribution rate as a percentage of wage.

$\mathrm{NAR} / \mathrm{wb}=$ present value of newly accrued rights as a percentage of wage bill.

Pens. exp./wb $=$ pension expenditure as a percentage of wage bill.

$(-) \mathrm{dIPD} / \mathrm{GDP}=$ negative of the change in Implicit Pension Debt as a percentage of GDP.

$\mathrm{B}(\mathrm{act}) / \mathrm{GDP}=$ budget balance under actuarial accounting rules as a percentage of GDP.

$\mathrm{B} / \mathrm{GDP}=$ budget balance under current national accounting rules as a percentage of GDP.

For assumptions, see the main text. 
Figure 4.5. Retirement age increase from 2005 onwards, accrual rates adjusted

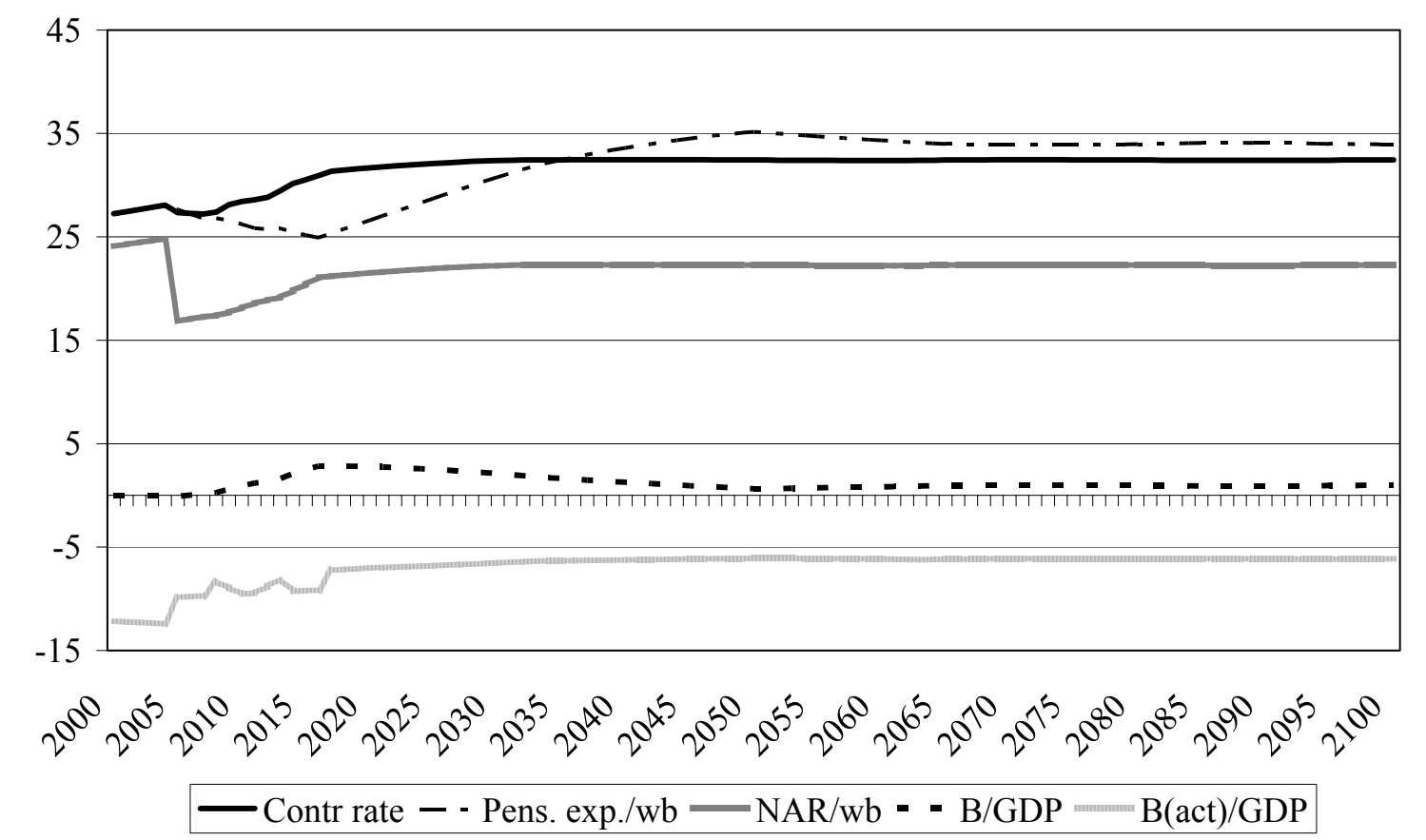

Contr. rate $=$ contribution rate as a percentage of wage.

$\mathrm{NAR} / \mathrm{wb}=$ present value of newly accrued rights as a percentage of wage bill.

Pens. exp./wb $=$ pension expenditure as a percentage of wage bill.

$(-) \mathrm{dIPD} / \mathrm{GDP}=$ negative of the change in Implicit Pension Debt as a percentage of GDP.

$\mathrm{B}(\mathrm{act}) / \mathrm{GDP}=$ budget balance under actuarial accounting rules as a percentage of GDP.

$\mathrm{B} / \mathrm{GDP}=$ budget balance under current national accounting rules as a percentage of GDP.

For assumptions, see the main text.

With regard to national accounting rules, it should be emphasised that actuarial accounting provides a robust base to cover a wide range of cases. Firstly, budget deficit under actuarial accounting gives the information about future pension expenditure at the moment of establishing the pension rights. If this deficit is higher than what was actuarially neutral, future generations pay an increasing burden. Secondly, deficit under this definition is the same irrespective of a wide range of institutional arrangements. This is in contrast to the sensitivity of the deficit under the current national accounting rules. The mandatory pension system is classified within government accounts if it provides defined benefits, even if partially funded, while a mandatory privately managed fully funded Defined Contribution (DC) system falls outside the government accounts. Institutional changes may therefore have a dramatic effect on government fiscal variables even in cases where the changes are actuarially neutral.

\section{Increasing retirement age}

In all scenarios above either the contribution rate increases or the replacement rate decreases significantly. If neither of these are acceptable, an increase in the age of retirement age is therefore triggered. As stated in Chapter 2, the 3-period model is adequate to calculate new sets of parameters for the new steady state with a higher retirement age, but not for the transitional period. This is also valid for the simulations using yearly data, as actuarial neutrality cannot generally be unambiguously defined for all such cases. 
To understand why, it is useful to note that full actuarial neutrality would be achieved in an extreme case where people retire from the public less-than-fully-funded pension system but continue working and paying contributions to a (mandatory or voluntary) fully funded and fully actuarial system. In this case they earn an addition to their replacement rate when they truly retire, but avoid paying the implicit tax to the basic public system. This case may have some relevance for grey economy activities of retired people but it is generally not the case under public pension systems, where it is, however, common and reasonable to prescribe specific accrual rates for workers around and beyond the average retirement age to provide proper incentives to work longer. If the accrual rates for older workers are less than actuarially neutral, then these workers are contributing to serving the implicit debt in this additional way, with the consequence that it is not possible to define perfect actuarial neutrality for any particular scenario. As the same already follows from the uniformity of the contribution rate for all age cohorts at each point in time, we have to accept that reality differs in many ways from the three-period model at hand. However, it can still serve as a framework for designing reform scenarios that follow the rule of actuarial neutrality as closely as possible.

Figure 4.5 gives an example of such a scenario. The accrual rates for working at ages 60,61 and 62 are simply assumed to be $1.25 \%, 3 \%$ and $4.5 \%$, and the retirement age to increase by three years, gradually, 0.3 years per year, i.e. over 12 years. The underlying idea is that the first one year increase might be possible without an increased accrual rate by tightening eligibility to disability pensions, but further increases require a noticeable compensation. As the purpose of the reform is to contain the increase in pension expenditure both in the short run and long run, it is also assumed that the accrual rate for the prime age workers is reduced from the initial $1.5 \%$ to $1.25 \%$ from 2005 onwards. These assumptions mean that after the full career of 43 years the replacement rate in the new steady state (after many decades) is $58.75 \%$, i.e. just below the initial $60 \%$.

This case is just an example, but interestingly these assumptions lead in the steady state to an IPD as a percentage of the wage bill that is roughly the same as in 2004, thus measured this way, the size of the public system remains unchanged in the long run. However, the contribution rate increases from $28.1 \%$ in 2004 to $32.4 \%$; this shows that containing this increase would require a further increase in the retirement age and/or a reduction in the accrual rate. The transitory decrease in expenditure due to the increase in retirement age and in the increase in contribution rate lead, in the long run, to an accumulation of assets by approximately $40 \%$ of GDP. These figures can be compared to the base case with prevailing benefits and retirement age, where contribution rate increases to $39 \%$ and assets to $95 \%$ of GDP.

\section{Proposal by Valdes-Prieto to securitize implicit tax and move instantaneously to full funding}

Valdes-Prieto (2005) advances a detailed proposal to securitize the implicit tax in the PAYG system, resulting not only in recording the IPD in the balance sheet of the public pension institution but also opening the possibility to trade a security that is closely linked to the rate of return on human capital. Although his blueprint could in principle be applied under defined benefit rules, his main motivation is to foster a pension reform that makes the system solvent under a specified contribution rate, and as a second step, insulate it from arbitrary political interference.

For the first stage, he proposes a transition from a tradition DB system to a Notional Defined Contribution (NDC; or Notional Accounts, NA, system). In broad terms, a transition to NDC from a public DB system means that contributions are fixed, registered 
on notional individual accounts which receive an administratively fixed rate of interest, and the capitalised value at retirement is transformed into an annuity paid out as a pension.

If the notional rate of interest is set as the rate of growth of the wage bill (which is the contribution base), and projections of life expectancy at retirement are continuously updated and correspond to the real outcomes, contribution revenue covers pension expenditure in the long run. However, this is not sufficient for financial stability (solvency) of the system. Revenue may in any given year be less (more) than pension expenditure due to a fall (increase) in participation rate, creating a deficit (surplus). If the interest rate is higher than wage bill growth, the system is financially unsustainable, unless the effect is by chance neutralised by another change. Therefore, an NDC system needs a specifically tailored balancing mechanism. ${ }^{9}$

Valdes-Prieto prescribes that the government creates "Covered Wage Bill" (CWB) bonds to restructure an NDC system (without financial assets). The right to collect the implicit tax under $\mathrm{PAYG}$ financed pensions is transferred from the government to the pension institution and this revenue is securitized into the CWB bonds, perpetuities held in the first place by the pension institution. Selling some of them to outside investors gives a daily valuation of these bonds. The financial rate of return earned by the pension institution is then used to determine the pensions to be paid out. This arrangement assures the financial balance of the scheme in every state of nature.

An assessment of the merits of this proposal based on improved allocation of risk is beyond the present paper. Here, it is interesting to note that both the implicit tax and IPD would be made explicit and recorded in the accounts of the pension institution. The consequences for government finances would depend on the interpretation and possible revision of national accounts classification criteria. On the one hand the newly restructured public pension scheme would resemble social insurance where the pensions are determined by the market rate of return on CWB bonds that is unknown ex ante. This could mean under the current rules that the pension institution be classified outside government sector in insurance corporations and pension funds, together with privately managed fully funded (mandatory and voluntary) pension schemes. On the other hand, the right of the newly structured public pension scheme to collect the implicit tax could be considered a characteristic due to which it should be classified within the government sector.

Be this as it may, this innovative proposal draws attention to basic features of public pension systems and the challenges of assuring their solvency. As Valdes-Prieto emphasises, his proposal can only be applied as a further step to a pension scheme that is solvent at the reform date. The present paper provides a framework for specifying a wide range of pension reforms that respect actuarial neutrality across generations and thereby provide a basis for solvency under fixed parameters.

\section{Implications for government finances and national saving}

Above, we have set actuarial neutrality as a benchmark and shown that, apart from a special case, the public pension system needs to depart from a pure PAYG. Importantly, a wide range of pension system rules fulfil this condition. Then, in general, explicit public debt net of financial assets - may decrease (as the pension system moves to partial funding), stay

\footnotetext{
${ }^{9}$ The Swedish NDC system incorporates such an adjustment mechanism also because its basic internal rate of return was originally set as the change of average wage rather than wage bill (see Settergren, 2001).
} 
constant or increase, depending on the future size of the public system. Note also that a reform may shift part of the mandatory system to the private sector, depending on the pension system and national accounting rules. Therefore, as said in Section 3 above, it is indispensable that the pension system and the rest of government finances are covered under an integrated framework when designing pension system rules and setting targets for public finances as a whole.

It is not self-evident that this is the case in practise. For example, if the public pension system is set to move to partial funding, but at the same time the target for government budget balance, as currently defined in national accounts, is independently set at a fixed number, then the surplus in pension fund would leak out as a consequent increase in deficit in the rest of government finances. Accumulation of funds for future pensions would then not serve its purpose.

Measuring this possible leakage, Bosworth and Burtless (2004) find that there was no leakage in the case of US States' budgets, while in 13 OECD counties over the period 1970-2000 slightly more than half seems to have leaked out. The authors conclude that preventing the leakage requires separating public pension funds from the rest of government finances. In their sample the leakage was smallest in Finland. This supports the view that a separate public pension system management structure, as in Finland, helps to achieve the intended effects of partial pre-funding of public pensions. In addition, in cases where the public pension system follows Defined Benefit rules, it is classified within the general government sector, the targets for general government must also be set so that the surplus and asset accumulation in the public pension fund separately enter into the targets for budget balance and net debt reduction.

Thus, setting the targets for government budget balance and net debt in line with the intended purposes of a pension reform is manageable under the current national accounting rules, provided that the key concepts are clarified and the required data is available. This can also be extended to possible pre-saving for future increases in other population ageing related public expenditure items like health care expenditure (for an application, see Oksanen, 2003).

Note also that if an appropriate rule for budget balance is followed, it does not matter whether the public pension fund invests in government bonds or in other assets. The resulting surplus will mean that explicit net public debt is decreased. If the budget balance target is set aside and a debt target is used instead, the target needs to be defined for explicit net debt as gross public debt will depend on the division of public pension fund investment between government bonds and assets issued by the private sector. Thus, if appropriate rules are followed, moving to partial funding as such does not require that the funds be invested in private equity, nor that management of these funds be privatised. These issues need to be decided on other grounds.

As compared to using the current national accounting concepts, the advantage of moving to actuarial accounting in setting fiscal targets is that the future pension expenditures, through the estimated IPD, possible pension fund assets and public debt, are inevitably incorporated into a consistent framework. Specifically, the newly defined budget balance and total explicit and implicit debt as a percentage of GDP are equal under all reform options that fulfil actuarial neutrality across generations. Correspondingly, a change in total debt ratio indicates a divergence from actuarial neutrality, whether it follows from pension system rules or from borrowing for public consumption. This allows examination of all relevant factors under an integrated framework, and definition of appropriate action should correction be required. 
As stated above, the simplicity and clarity of the results above are partly based on the simple assumptions that the interest rate is at a constant margin $\bar{d}$ above the growth rate of the wage bill. Apart from deriving the interest rate from a general equilibrium model, which is outside the scope of the present partial and practically oriented analysis, this assumption is as good as any other simple assumption, for example that the real interest is constant. We can interpret the assumption on a constant $\bar{d}$ to indicate that the economy stays at a constant distance from the Golden Rule of elementary growth theory that implies this margin to be zero. Here, the advantage of a constant $\bar{d}$ is that it leads to simple results. Furthermore, nothing prevents the assumption of a different margin for different scenarios depending on the accumulation of capital in each, for example. It is also relatively easy to apply the present framework to cases where the perceived interest rate margin changes from one point in time to another.

As explained at the end of section 2, actuarially neutral combinations of pension system parameters can be set by always applying the same $d_{t}$ for calculating the implicit tax and present value of future pensions, and recording a capital gain or loss if $d_{t}$ changes. The same applies to setting the targets for government debt and deficit. It is advisable to assume a fixed $\bar{d}$, and if and when it changes for whatever reasons, record the consequent capital gains or losses, and revise the target for government debt. Note that this is conceptually similar to treating the gains and losses from fixed coupon perpetuities caused by changing the market interest rate. These financial instruments are used for government debt as an alternative to fixed maturity (one generation) loans assumed in our model above. ${ }^{10}$

Another important factor that requires special attention concerns longevity and retirement age. The basic model above assumes that retirement age is fixed and longevity is correctly foreseen. Generally, retirement age will increase and alleviate the increase in the contribution rate and compensate for the decrease in the accrual rate. As said above, specific accrual rates are often applied for the years around the standard retirement age, but these do not generally provide full compensation for lengthening the career. This way, older workers partly pay for the implicit debt. Such a revision of pension system parameters and their expected effects on retirement age reduce IPD, which should be fed into a revised government debt target. This complicates the exercise, as revisions to accrual and contribution rates and their projected effects on peoples' behaviour enter the calculation. However, accounting for these factors in a consistent way is necessary for any rational designing of public policy measures for increasing the retirement age and assessing their effects. The framework provided here gives some guidance, although the benchmark of actuarial neutrality can in reality always be only be approximated.

\section{Pension reforms and total saving}

\footnotetext{
${ }^{10}$ The assumption on the interest rate can be very important in many applications. For example, interpreting the simulation results reported by Fenge and Werding (2004) for implicit taxes in selected OECD countries, it is useful to note that the expression for implicit tax under actuarial neutrality in equation (14) above states that the implicit taxes may increase not only due to an increase in total net debt but also due to an increase in the interest margin. Consequently, if the interest rate is assumed to be fixed and the rate of economic growth decreases, the interest margin increase induces an increase in implicit tax. Therefore, if the purpose of a simulation is to use implicit tax as a measure of the relative position of each generation, it would be more advisable to technically assume a fixed interest margin and treat the effects of its change separately if necessary.
} 
Looking at public pension in a partial analysis, as above, without doubt provides a framework for discussing their reforms. However, the effects on the real economy also depend on the behaviour of the private sector, which may crucially affect the choice between alternative reforms.

The extreme case at a high level of abstraction, the so-called Ricardian equivalence revived by Barro (1974) - provides a starting point: though a lifetime is finite, assuming that people give the same weight to their own discounted utility and that of their descendents, they behave as if it were infinite; therefore, under perfect markets, an increase in government debt is matched by an increase in private saving as people want to leave to their heirs a quantity of wealth that also covers the present value of future taxes to serve public debt. This implies, for example, that introduction of a pure PAYG pension system would not affect total saving (and therefore no real economy variables) as people would accumulate a stock of private saving that matches government IPD. More generally, whatever happens to government debt, whether explicit or implicit, does not have any real effects.

This theorem is as good as its assumptions. It has served to challenge other extreme views on the effects of government intervention, and as its implications have not been considered to be fully plausible, it has also guided further research to relax one or another of its assumptions. ${ }^{11}$

Maintaining the assumption of perfect markets, one obvious alternative assumption is that people plan their saving over their own lifetime and that they do not leave bequests, or at least the bequests are not fully affected by government finances. Then, not only deficit spending by the government reduces total saving, but also introduction of a pure PAYG pension system reduces private saving as people save less for their own retirement. Incidentally, Feldstein (2005a) looks back on his time as a graduate student in the 1960s and remembers how he became interested in pensions, having noted that Friedman's and Modigliani's work on life cycle saving completely ignored their role even though they had become the major source of retiree income.

The inference highlighted in the present paper is that under given Defined Benefit pensions, population ageing leads to an expansion of the pension system that should be understood to have the same effect on private saving as the original introduction of a pure PAYG system. Total public debt, i.e. explicit debt and IPD (as a proportion of the scale of the economy) is a most relevant measure of public intervention. Even if explicit net public debt is constant, yet the benefit rules are maintained under a pure PAYG system under population ageing, total public debt increases and total saving declines.

What then will happen to saving under population ageing and actuarially neutral pension system rules? Assume that initially a public pension system provides some level of retirement income but less than what people need under an exogenously determined retirement age and a given target for consumption at retirement. Then, under population ageing, saving must increase as people will spend longer time in retirement and the rate of interest is lower due to declined rate of economic growth. This increase is the same under

\footnotetext{
${ }^{11}$ See e.g. Kotlikoff (2002) and Wyplosz (2004) for discussions on implicit liabilities, deviations from Ricardian equivalence and public finances.
} 
any actuarially neutral pension system rules as the level of future pensions only determines the division of saving between mandatory and voluntary. ${ }^{12}$

This positive effect on saving is only transitional. In the new steady state with a stable population age structure the saving rate may, under the assumptions above, be lower than initially, i.e. before the long process of population ageing started. However, the capitaloutput ratio (or capital-labour ratio) is higher than initially - the declined rate of growth of the economy due to the shrinking labour force explains that net saving rate which keeps the capital-output ratio at its new higher constant level is lower than initially (this is also consistent with the observation that the number of pensioners who dissave to that of workers who save is now higher than initially).

However, in the first phase of the transition, with no further government intervention (i.e. installing actuarially neutral pension system rules), workers' saving rate must increase as their targeted pension capital increases. This effect is important because, even if transitional, it may last for a couple of decades because the underlying process of population ageing is so slow, taking some two to three generations depending on the initial impulse triggering it. For this reason, an analysis confined to a comparison of alternative steady states is inadequate, and potentially misleading.

The comments above help in assessing the empirical studies on the effect of population ageing on private and total saving (see e.g. Loayza, Schmidt-Hebbel and Servén, 2000, and Samwick, 2000; for a review see McMorrow and Röger, 2004). These studies normally build on the life-cycle saving models, but fail to address the time factor consistently with the underlying theory: it takes 30 years for an average worker (age 40) to become an average pensioner (age 70); therefore, his/her savings decisions will depend not on what the population age structure is nor what pensions of current pensioners are now, but on what he expects them to be 30 years hence. Nor does observing the characteristics of the public pension system today with regard to degree of funding, for example, give an adequate picture, as while the degree of funding might remain at zero, pension system generosity may change significantly. Therefore, any empirical study requires a careful specification of pension system rules and their changes in order to obtain useful results on the effect of population ageing on saving under alternative pension system rules.

Another body of recent literature presents simulation results based on the life-cycle (or overlapping generations, OLG, models). Saarenheimo (2005) recognises the positive effect of population ageing on saving stemming from the increase in saving by prime age workers as they need to plan for longer retirement than before. He therefore shows results where, in the first place, saving increases, real interest rates decrease and the 'financial market meltdown' feared by some other authors does not happen. Also Krüger (2004) explains and illustrates the same important implication of the life cycle model. As discussed above, this increase in saving shows up in the private or public sector depending on public pension system rules. An analysis with a broader scope is provided by Börsch-Supan et al. (2005) who analyse population ageing and a pension reform in the major continental EU countries that can be judged to be roughly actuarially neutral in language here. They show simulations with a positive effect of pension reform on household saving. Their emphasis is on the beneficial side effects of additional saving through capital markets that increase total productivity. Importantly, in their simulations, the household saving rate declines in the base line scenario to an extent that the positive effect of the fundamental pension reform is

\footnotetext{
${ }^{12}$ For the sake of the argument, the target for consumption at retirement was assumed to be given. Under a full life-cycle model, the decrease in the interest rate due to a decrease in growth alters the targeted ratio between consumption during working career and retirement, reducing the implicit replacement rate.
} 
not able to turn it around fully. The reason is that, initially, under generous public pensions, household saving is dominated by other motives than saving for retirement and that these other savings are reduced when people voluntarily start saving more for their retirement.

A comparison of these various simulation studies indicate that the results crucially depend on the assumptions made, and it has to be acknowledged that no definite results are available on private saving under the projected large changes in demographics and wide range of pension reform options that should be considered. A prudent conclusion should be, however, that total saving should temporarily increase under actuarially neutral pension reforms, and if there are factors that prevent this from happening, then the need for public policy measures to keep it up is amplified.

\section{The controversy over mandatory private pension accounts in the US}

The framework in the present paper can be used for commenting on the heated debate on US Social Security pensions. Feldstein (2005a and 2005b) maintains that shifting a fraction ( $1.5 \%$ of wages) of mandatory pension contributions to newly created private accounts, and topping this with a similar additional contribution would provide benefits that would exceed those foreseen under the current rules, thus eliminating any need to increase the contributions otherwise foreseen, so that every generation would gain. In short, his argument is that the pension system is an appropriate vehicle for increasing aggregate saving which is currently lower than optimal, and that replacing part of the tax on wages by mandatory pension savings partly eliminates the harmful distortion of labour supply.

It should be observed that Feldstein's arguments, if valid, apply equally well under stable population structure as under population ageing. Also, by implication, under his assumptions, establishing a pure PAYG pension system (as with issuing public debt for consumption) cause a net loss over all generations, deviating from the analysis above that equates the gain to one generation to the cost to be borne by all future generations together (for a more general presentation, see Feldstein and Liebman, 2002).

The camp opposing private accounts is not convinced of their merits as they assert that the alleged positive effects can also be achieved by other means, for example, by removing distortions in labour and capital markets and thereby enhancing production and total saving. For them, financial sustainability of the pension system can be assured with reforms under the current institutional structure. Diamond and Orszag (2004 and 2005) present such a detailed plan that implies a moderate contribution rate increase and roughly constant benefits for currently older cohorts followed by modest reductions.

In assessing the proposals of both camps we should first note the unanimous desire not to deviate far from the current average replacement rates of roughly $30 \%$; in fact, Feldstein's proposal foresees increasing total benefits, helping to convince the audience that it is advantageous to everybody. Maintaining the benefit level might be an advisable base line for the US as it is roughly half the level in European welfare states, and cuts would lead to poverty among the elderly population. Thus, the necessary adjustments need to be made in contribution rates and retirement age. Secondly, we should note that the demographic development is less worrying in the US, mainly due to the higher fertility rate.

A rough back of an envelope calculation shows that the principle of actuarial neutrality across generations as developed above would lead after two generations, to a $25 \%$ of GDP increase in the Trust Fund, on top of its current level of about $10 \%$ of GDP. The DiamondOrszag plan implies a temporary increase in the Trust Fund (to smooth out the effects of the baby boom generation) and a consequent levelling off to its current level as a percentage of 
GDP. Feldstein's proposal implies that capital on the mandatory private retirement accounts would reach $100 \%$ of GDP in 2060 . This may exceed actuarial neutrality and put a greater burden on the transition generation than on others. However, it is not possible to take a firm view on this as his plan is based on the arguments about improved efficiency, and thereby gains to all generations.

Here, we do not want to take a view on the possible efficiency gains from introducing private accounts into the US system. As for the Diamond-Orszag proposal, most importantly, it assures financial sustainability of a system that provides benefits at roughly current level. From the perspective of burden sharing across generations, it seems that the increase in contribution rate could be slightly frontloaded, leading to an increased Trust Fund in the long run, though a more refined view of such an adjustment would require examination of other related factors.

\section{Old Europe is different}

In European welfare states the public pension systems currently provide benefits with double the generosity of that in the US, and population ageing will drastically shift the terms under which they can be financed. Respecting the accrued rights, a balanced package for future probably includes a reduction in benefit level and an increase in retirement age, but an immediate increase in the contribution rate and thereby a move to some degree of partial funding might be required for actuarial neutrality. Partial funding of the mandatory pension system should then lead to a reduction of public net debt, or to establishing a separate fully funded, possibly private sector managed second pillar. Both solutions lead under plausible assumptions to an increase in total saving. This conclusion can be reached from relatively simple arguments, without entering into more complicated and controversial ones about market distortions and efficiency gains.

Recalling that public pension systems, largely pure PAYG based, were established in the late 1950 s or early 1960s in many European countries, we can infer that an extraordinary gain was paid to the first generation, which the future generations must pay for. However, referring back to Figures 1.1-1.3 above, a more complete judgement needs to be based on government finances as a whole: the workers in the 1950s through mid-1970s saved collectively as net saving of government was $2-3 \%$ of GDP in our sample of EU countries. This could have compensated for the negative effect on saving and growth that would otherwise have resulted from the introduction of generous public pensions.

Since the mid-1970s, as pension systems approached maturity, the decline in fertility and increase in longevity induce, if pension generosity is preserved, a gain to the generation currently of working age that is similar to that for the first generation of retirees. This time, the difference is that government saving has declined and it is also hard to identify any other mechanism that would compensate for the increasing pension burden.

\section{Conclusions and suggestions for further work}

Perhaps the main motivation to present this relatively simple analysis of public pension systems is that people know very little about their functioning (see for example the survey results in Boeri, Börsch-Supan and Tabellini, 2001 and 2002, covering four major EU countries). They may have an idea as to the rights they have earned (or what earnings they think would be justified over their full career), but the costs of pensions, and who will or should bear them is obviously very poorly understood. As an aid to informed discussion, 
the present paper develops a framework for establishing the link between costs and benefits by defining as a benchmark an actuarially neutral division of costs across generations as population ageing takes place, i.e. successive generations are different with regard to their demographic characteristics.

As a starting point the framework gives a scenario where the replacement rate and retirement age are assumed to be constant. The scenario shows what the current workers should pay for future accumulation of pension rights if they do not want to leave an increasing financial burden to future generations. Any imbalance in the past is taken for granted, and the burden is shared equally across the current and future generations, relative to the wage bill. For most welfare states, this gives a result that pension contributions should be significantly increased, leading to partial funding. Even if the contribution rate would be less than the increase in expenditure in the long run, this first result would give analysts and policy makers the impetus to infer that an accumulation of pension rights should be revised downwards and retirement age should be increased. Thus, a full range of actuarially neutral scenarios opens up for discussion, including establishing a fully-funded private sector managed second pillar.

The three-period model and the illustrations with yearly stylised data form a minimal exercise to present the key conclusions. The assumed public pension system and its economic environment are very simple. However, adding more details and, for example, introducing uncertainty into the economic environment would give an insight into the more general situations but the main conclusions and orders of magnitude would remain.

Defining actuarial neutrality across generations provides a framework for examining pension systems, notably to avoid any unintended increase in the pension burden. It is a benchmark that defines an infinite number of reform options that differ with respect to the future level of benefits and organisational features, such as sharing the management in a mandatory system between public authorities and privately managed pension funds.

The criteria used to choose among these options boil down to the same issues as are relevant in the initial introduction of a public pension system: moral hazard and imperfections in the private annuities market, and paternalism towards those who are believed to be myopic. When considering reform to relatively generous public pension systems in European welfare states, it is plausible that the best option is a combination of more than one institutional arrangement, and their relative size should change under population ageing.

Implicit Pension Debt, alongside implicit tax, is a key concept in the analysis above. Estimating IPD is not an easy task as pension system rules may be ambiguous and the results depend on the assumptions of various factors, e.g. the interest rate. However, an exercise to produce a range of estimates under alternative interpretations of the prevailing rules and other assumptions, accompanied by estimates under proposed pension reform options is not only useful for actuaries and other analysts. Besides this, it can be considered to be a public authority obligation in order to inform the workers and the general public of their pension rights. Only then can the citizens make informed decisions on their private and voluntary saving pattern for retirement.

While estimates on IPD in EU and other OECD countries date from the early 1990s and are outdated (see Franco et al., 2005), long-term projections on public pension expenditure are now produced for most countries. Producing estimates for IPD would be based on the same data, with the refinement that the calculations would need to be made by age cohorts. This is a challenging, but without doubt, an instructive task that has already been undertaken for 
quite a few countries. Holzmann et al. (2004) covers middle income countries whilst Takayama (2005a) gives estimates for Japan that include the IPD accumulated up until now and roughly indicates that under the recently reformed rules, IPD would not increase further. Thus, it seems that the reform roughly complies with actuarial neutrality. His main worry, expressed in Takayama (2005b) is that the contribution rate envisaged is too high, causes distortions, and might not be sustainable. Werding (2005) gives estimates for IPD in Germany under previous legislation and various reform acts since $1992 .{ }^{13}$

As for incorporating the estimates for IPD and the consequent general government debt and budget balance into national accounts and monitoring government finances, many analysts remain hesitant, as imprecision in estimating IPD and revisions due to changing assumptions would hamper enforcement of fiscal rules (see e.g. Balassone et al., 2004, and Franco et al., 2005). However, refraining from this challenging effort could be criticised, as Wyplosz (2004) puts it, as concentrating on improving "the precision of what we already know while ignoring the more important information because it is imprecise". There is no perfect solution to this genuine dilemma, especially as the difficulty in defining and measuring the IPD across countries varies enormously, making internationally applicable solutions most difficult. For the time being, the compromise solution proposed by Lequiller (2005) for national accounting is one that would incorporate the actuarial estimates in supplementary accounts. Regardless of possibly sticking to the current national account definitions for setting targets for government debt and deficit for the medium term, it is obvious that future pension liabilities should be taken into account. The projected changes in the demography and potential reforms to pension system rules are factors that should be an essential part of the picture, as they imply significant changes to debt and the budget balance. This was demonstrated above with stylised data and actuarial neutrality, but it is obviously valid more generally.

The approach here and its implications for policy are normative in the sense that they provide a framework for policy design. However, the approach in no way dictates that any specific policy should be adopted. It provides a benchmark that applies the concept of actuarial neutrality in private insurance to public policy, including sharing the burden of explicit and implicit debt, but it is ultimately for the decisions made on policy whether or not this benchmark is followed or deviated on purpose. In any event, the framework presented here is a useful basis for an informed discussion to take place.

One general implication of the benchmark for neutrality is that with population ageing currently on-going in the European welfare states, the total saving rate increases over the next few decades, and that this should be supported either directly or indirectly by public policy. This inference is based on the view that people are not ready to take the alternative route and soon accept an increase in the effective retirement age by at least five years or living with significantly reduced pension benefits. Note that we have not incorporated public health care costs into our analysis. This could be done in a straightforward way as older generations require more health care than the young. Consequently, by adopting the principles for pensions under actuarial neutrality, people ought to begin pre-financing their future health care whilst still in employment. This would add to the increase in saving.

\footnotetext{
${ }^{13}$ The generational accounts developed by Kotlikoff and others, see e.g. Kotlikoff (2002), broadly tackle the IPD and its future changes, typically calculating the net tax payments for the current population and for all future generations under the assumption that taxes need to be increased to cover expenditure, and noting the difference as an imbalance in the system. The framework in the present paper can be seen to capture the same approach with regard to public pensions, emphasising the link between contributions and benefits, and attempting to look as closely as possible to gradual adjustment to follow actuarial neutrality under the prevailing and reformed rules.
} 
The validity of the general result for the increase in saving presupposes that our economies are not currently in a persistent saving glut, nor in any immediate danger of entering into one. This is, according to mainstream economics, proven by the observation that the marginal product of capital (including investment in human capital) exceeds the rate of growth of the economies.

Finally, in a long-term analysis of saving and capital we should not lose sight of human capital formation. With reduced fertility, leading to decreasing numbers in the labour force, it should noted that, at least in principle, an increased level of child education could compensate in part for the fall in fertility, leading to more qualified labour. It is unlikely, however, that the level of education invested in, both individually and collectively by workers and tax payers, would have increased to the extent that this saving and investment would have compensated the effects of population ageing. For the future, if and when important reforms in the education system and its financing take place, they should be considered in parallel with pension reforms.

\section{REFERENCES:}

Balassone, F., Franco, D. and Zotteri, S. (2004), "EMU fiscal indicators: a misleading compass?", XVI Villa Mondragone International Economic Seminar on "Rules, International economy and growth", CEIS University of Rome "Tor Vergata", June $23^{\text {rd }}-24^{\text {th }}, 2004$.

Barro, R.J. (1974), “Are Government Bonds Net Wealth?”, Journal of Political Economy, vol. 81, no 6, pp. 10951117.

Boeri, T., A. Börsch-Supan and G. Tabellini (2001), "Would you like to shrink the welfare state? A survey of European citizens", Economic Policy (32), pp. 9-44.

Boeri, T., A. Börsch-Supan and G. Tabellini (2002), "Pension Reforms and the Opinions of European Citizens", American Economic Review, vol. 92, pp. 396-401.

Bosworth, B. and Burtless, G. (2004), "Pension Reform and Saving", The Brookings Institution, manuscript, January 5, 2004, revised.

Börsch-Supan, A., Köke, F.J. and Winter, J. (2005), "Pension reform, savings behaviour, and capital market performance", Journal of Pension Economics and Finance, 4(1): 87-107, March, 2005.

de Rougemont, Ph. (2003), "The Treatment of Employer Retirement Pension Schemes in Macroeconomic Statistics - The EDG on Pensions December 2003 Report", the Report of the Moderator of the Electronic Discussion Group (EDG), at http://www.imf.org/external/np/sta/ueps/index.htm

Diamond, P.A. and Orszag, P.R. (2004), Saving Social Security, A Balanced Approach, Brookings Institution Press, Washington, D.C.

Diamond, P.A. and Orszag, P.R. (2005), "Saving Social Security", Journal of Economic Perspectives, vol. 19, no 2. Spring 2005, pp. 11-32.

Esping-Andersen, G., Gallie D., Hemerijckn A. and Myles J. (2002), Why we need a new Welfare State, Oxford, Oxford University Press.

Eurostat news release of 21 October, 2003, "New decision of Eurostat on deficit and debt, Payment to government by public corporations in the context of the transfer to government of their unfunded pension obligations".

Eurostat news release of 25 February, 2004, "New decision of Eurostat on deficit and debt, Payment to government by public corporations in the context of the transfer to government of their pension obligations".

Eurostat news release of 2 March, 2004, "New decision of Eurostat on deficit and debt, Classification of funded pension schemes in case of government responsibility or guarantee".

Feldstein, M. (2005a), "Rethinking Social Insurance”, American Economic Review, vol 95, no 1, pp. 1-24. 
Feldstein, M. (2005b), "Structural Reform of Social Security", Journal of Economic Perspectives, vol. 19, no 2. Spring 2005, pp. 33-55.

Feldstein, M. and Liebman J. B. (2002), "Social Security", in Handbook of Public Economics, Vol. 4, edited by Alan J. Auerbach and Martin S. Feldstein, Amsterdam and N.Y., North Holland.

Fenge, R. and Werding, M. (2004), “Ageing and the Tax Implied in Public Pension Schemes: Simulations for Selected OECD Countries”, Fiscal Studies, vol. 25, no. 2, pp. 159-200.

Franco, D., Marino, M.R. and Zotteri, S. (2005), "EU Fiscal Rules: the Role of Pension Expenditure Projections and of Pension Liabilities", Proceedings No. 6, "The Balance Sheet of Social Security Pensions”, Institute of Economic Research, Hitotsubashi University, February, 2005.

Holzmann, R., Palacios, R. and Zviniene, A., (2004), "Implicit Pension Debt: Issues, Measurement and Scope in International Perspective", No 0403, Social Protection Discussion Paper Series, the World Bank, at http://www1.worldbank.org/sp/

Kotlikoff, L.J. (2002), "Generational Policy", in Handbook of Public Economics, Vol. 4, edited by Alan J. Auerbach and Martin S. Feldstein, Amsterdam and N.Y., North Holland.

Krüger, D. (2004), “The Effects of Demographic Changes on Aggregate Savings: Some Implications from the Life Cycle Model", in Capital Markets in the Long Term: Demography, economic Development and Funded Pension Systems, Center for Financial Studies and Allianz, Frankfurt am Main, 2004.

Lequiller, F. (2005), "Towards a compromise for the new SNA", August 2005, at the Electronic Discussion Group (EDG) website http://www.imf.org/external/np/sta/ueps/index.htm.

Loayza, N., Schmidt-Hebbel, K. and Servén, L. (2000), “What drives private saving across the world?", The Review of Economics and Statistics, May 2000, 82(2): 165-181.

Mc Morrow, K. and Roeger, W. (2004), Economic and financial market consequences of ageing populations, Spriger, Berlin. Also No 182, European Economy, Economic Papers, Directorate-General for Economic and Financial Affairs, European Commission, April 2003, European Commission. Brussels.

Musgrave, R.A. (1986), "Public Finance in a Democratic Society" in Volume II "Fiscal Doctrine, Growth and Institutions", Chapter 7. Wheatsheaf Books Ltd, Brighton.

Myles, J. (2003), "What justice requires: pension reform in ageing societies", Journal of European Social Policy 13(3), $264-269$.

Nishiyama, S. and Smetters, K. (2005), "Does Social Security Privatization Produce Efficiency Gains?", Michigan Retirement Research Center, Working Paper, WP 2005-106.

OECD Statistics Directorate (2004), "Conditions for the proposed change in the treatment of unfunded employer pension schemes in the SNA: illustration for general government accounts", January 23, 2004, at the Electronic Discussion Group (EDG) website http://www.imf.org/external/np/sta/ueps/index.htm.

Oksanen, H. (2003) "Population ageing and public finance targets", No 196, European Economy, Economic Papers, Directorate-General for Economic and Financial Affairs, European Commission, December 2003.

Oksanen, H. (2004) "Pension Reforms: an illustrated basic analysis", in CESifo Economic Studies, 3/2004. Also No 201, European Economy, Economic Papers, Directorate-General for Economic and Financial Affairs, European Commission, April 2004.

Oksanen (2005a). “Actuarial Neutrality across Generations Applied to Public Pensions under Population Ageing: Effects on Government Finances and National Saving", No. 230, European Economy, Economic Papers, Directorate-General for Economic and Financial Affairs, European Commission, July 2005, and as No. 1501 CESifo Working Paper (Munich, Germany).

Oksanen, H. (2005b) "Public pensions in the national accounts and public finance targets", Journal of Pension Economics and Finance, 4(3): 291-312, November, 2005.

Saarenheimo, T. (2005), “Ageing, interest rates, and financial flows”, Bank of Finland Research, Discussion Papers, 2/2005.

Samuelson, P.A. (1958), “An exact consumption-loan model of interest with or without the social contrivance of money”, Journal of Political Economy, LXVI, pp. 467-482.

Samwick, A. (2000), "Is pension reform conductive to higher saving?", The Review of Economics and Statistics, May 2000, 82(2): 264-272. 
Schokkaert, E. and P. Van Parijs (2003), “Social Justice and the Reform of Europe's Pension Systems”, Journal of European Social Policy 13(3), 245 -263.

Settergren, O. (2001), “The Automatic Balance Mechanism of the Swedish Pension System - a non-technical introduction”, Wirtschafts Politische Blätter (4), 339-349.

Sinn, H.-W. (2000), "Why a Funded System is Useful and Why it is Not Useful". International Tax and Public Finance, 7, pp. 389-410.

Statistics Department, International Monetary Fund (2004), “The Statistical Treatment of Employers' Pension Schemes", December 2004, at the Electronic Discussion Group (EDG) website http://www.imf.org/external/np/sta/ueps/index.htm.

Takayama, N. (2005a), "The balance sheet of social security pensions in Japan", Proceedings No. 6, "The Balance Sheet of Social Security Pensions", Institute of Economic Research, Hitotsubashi University, February, 2005.

Takayama, N. (2005b), "Social Security Pensions and Intergenerational Equity: the Japanese Case", Discussion Paper 282, Project on Intergenerational Equity, Institute of Economic Research, Hitotsubashi University, October, 2005.

Uebelmesser, S. (2004), Unfunded Pension Systems: Ageing and Migration. Elsevier, Amsterdam.

Valdes-Prieto, S. (2005), "Securitization of taxes implicit in PAYG pensions", Economic Policy, April 2005, pp. $215-265$.

Werding, M. (2005), Implicit Pension Debt and the Role of Public Pensions for Human Capital Accumulation: An Assessment for Germany", paper given at "The Second International Workshop on the Balance Sheet of Social Security Pensions", Hitotsubashi Collaboration Center, Tokyo, 15 December, 2005 (in this volume).

Wyplosz, C. (2004), "Large and Unknown Implicit Liabilities: Policy Implications for the Eurozone”, paper given at "Fiscal Surveillance in EMU: New Issues and Challenges", a workshop organized by the European Commission, Directorate General for Economic Affairs, in Brussels on 12 November 2004, available at http://europa.eu.int/comm/economy_finance/events/2004/events_brussels_1104_en.htm. 